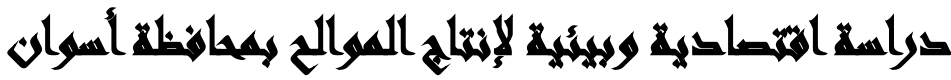

\section{ولاء عبد الجواد مصطفى أحمد(')- سهام أحمد عبد الحميد هاشم(ץ)}

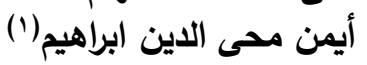

() معهد بحوث وقاية النباتات، مركز البحوث الزراعية r ب) كلية الدراسات العليا والبحوث البرات

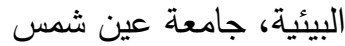

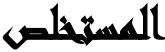

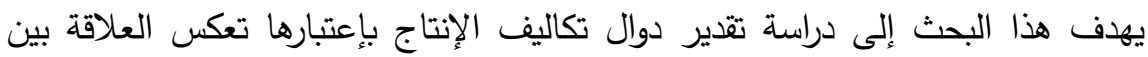

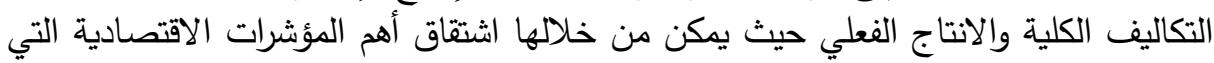

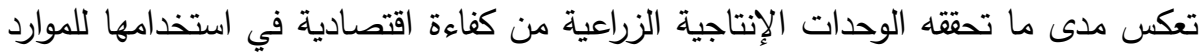

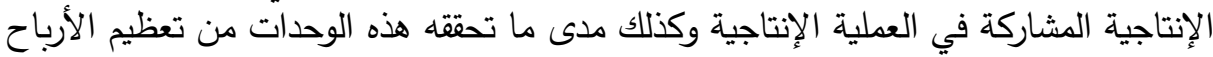

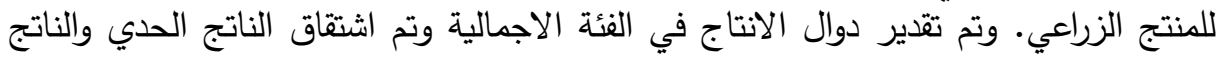

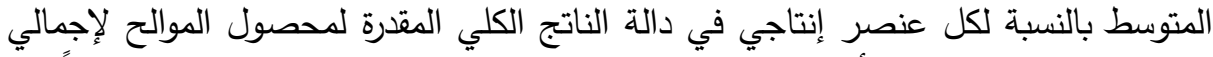

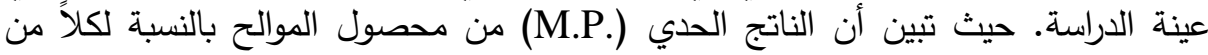

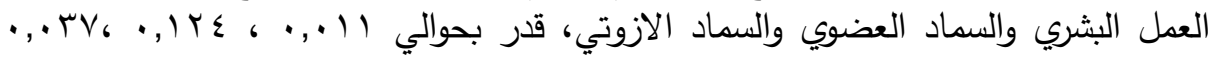

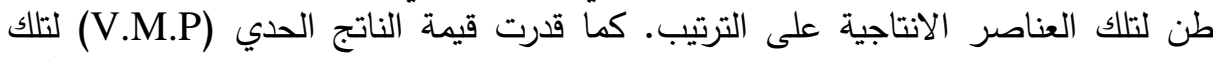

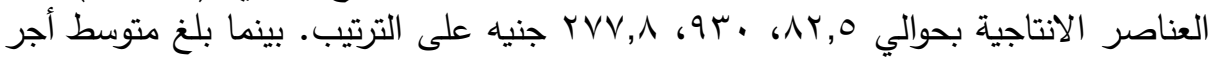

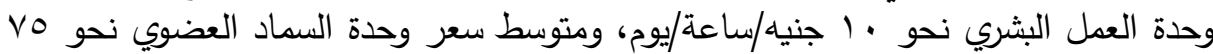

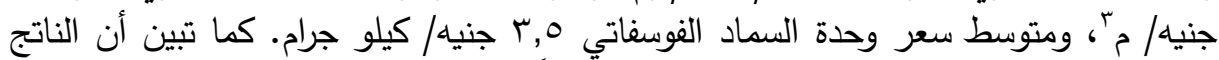

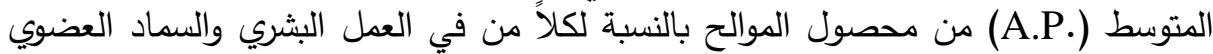

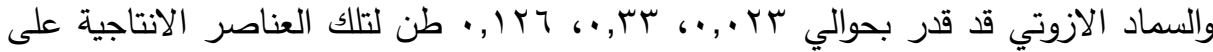

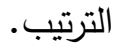
الكلمات الدالة: دوال التكاليف، دوال الانتاج، الكفاءة الاقتصادية، الحجم الامثل للانتاج.

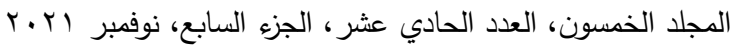

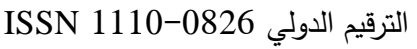

$$
\begin{aligned}
& \text { الترقيم الدولي الموحد الإلكتروني 3178-2636 }
\end{aligned}
$$




\section{المهيتها}

يعتبر محصول الموالح من اهم المحاصيل البستانية الواعدة بمصر وتتميز محافظة

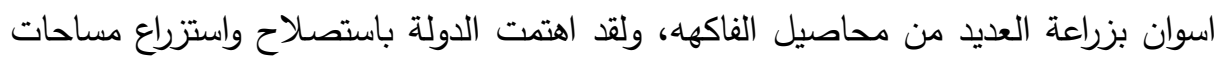

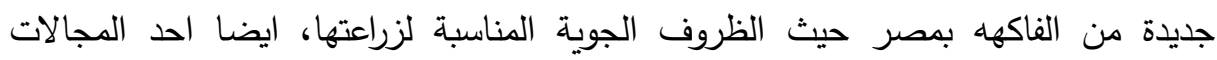

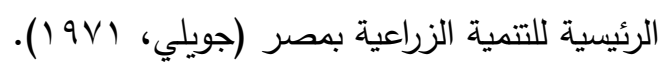
يهدف هذا البحث إلى دراسة تقدير دوال تكاليف الإنتاج بإعتبارها تعكس العلاقة بين

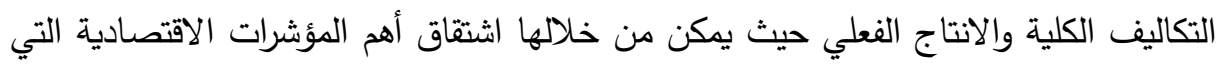
تعكس مدى ما تحققه الوحدات الإنتاجية الزراعية من كفاءة اقتصادية في استخدامها للموارد الإنتاجية المشاركة في العملية الإنتاجية وكذلك مدى ما تحققه هذه الوحدات من تعظيم الأرباح

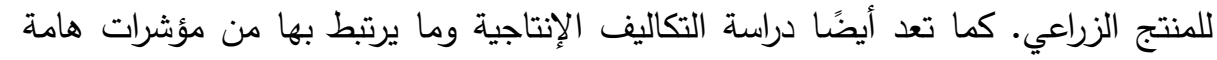
سواء على مستوى الوحدة الانتاجية او على المستوى القومي، حيث يمكن الاستعانة بها في لئه رسم وتحليل السياسات السعرية ومساعدة المنتجين الزراعيين في اتخاذ القرارات الإنتاجية

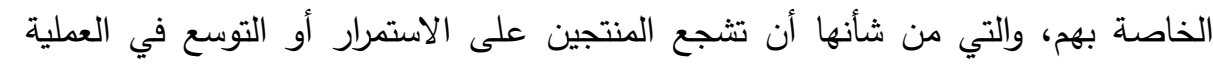

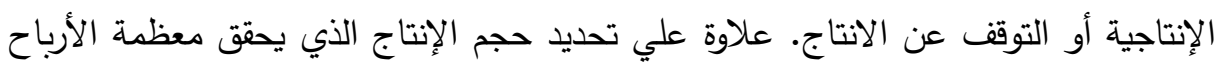

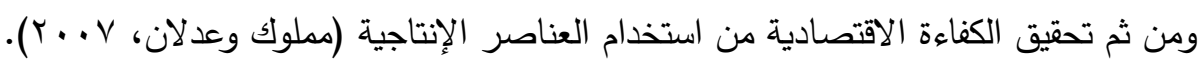

\section{andilland}

تتلخص المشكلة فى في وجود تباين واسع النطاق في حجم مزارع الموالح في محافظة

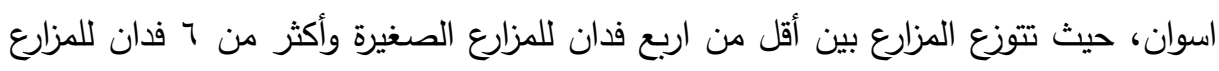

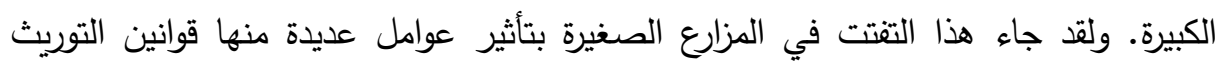
والقوانين والتشريعات المنظمة الاستقلال الأراضي الجديدة وتكون مقتصرة على كبار

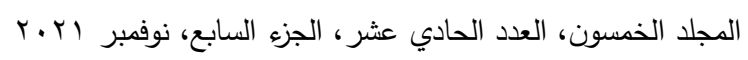

$$
\begin{aligned}
& \text { الترقيم الدولي التي التوني } \\
& \text { الترقيم الدولي الموحد الإكتروني 3178-2636 }
\end{aligned}
$$


المستثمرين، لذلك اتجهت العديد من الدراسات في الآونة الأخيرة نحو محاولة تحديد الحجم

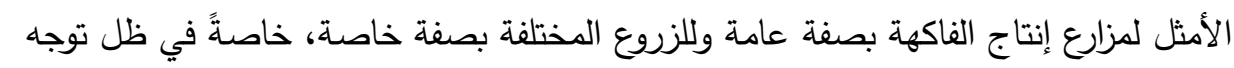

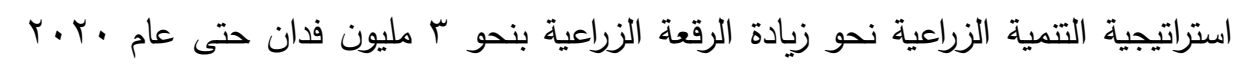

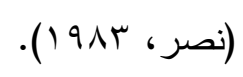

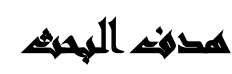

يهدف البحث الى دراسة تقديره لدوال الانتاج التعرف على اهم عناصر الانتاج المحددة

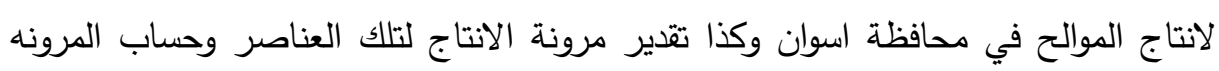
الاجمالية المحددة لطبيعة المرحلة الانتاجية كما يهدف هذا البحث من خلال تقدير دوال التكاليف إلى قياس الحجم الأمثل لمزارع الموالح في الأراضي الجديدة بالمحافظة وتحديد عوائد

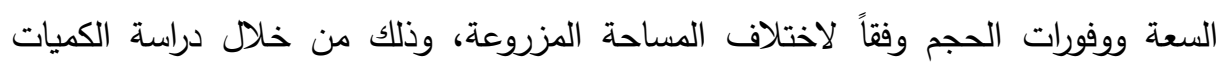
الفيزيقية والقيم النقدية للمدخلات الزراعية وفقاً لاختلاف حجم المزرعة وتقدير الأهمية النسبية

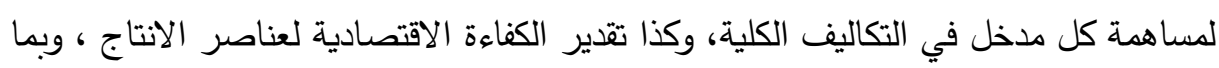
يمكن من الاستفادة القصوى من عناصر الانتاج المتاحة (رضوان، (99 (1)).

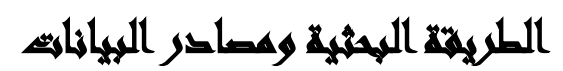

اعتمدت الدراسة في تحقيق اهدافها على البيانات الأولية التى تم الحصول عليها من

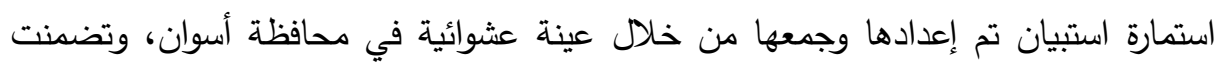
عملية تحليل البيانات استخدام بعض المعايير الإحصائية الوصفية والكمية المتمثلة في

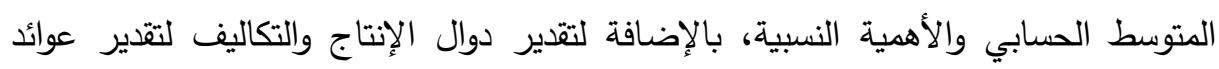

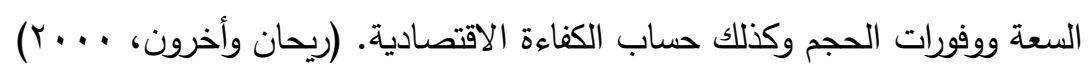

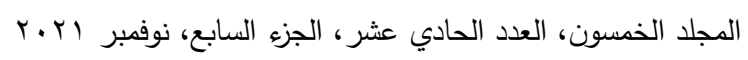

$$
\begin{aligned}
& \text { الترقيم الدولي التي التوني } \\
& \text { الترقيم الدولي الموحد الإكتروني 3178-2636 }
\end{aligned}
$$


تم اختيار محافظة اسوان مركز ابو سمبل قرية السلام بتوشكى وفقاً للأهمية النسبية لمساحة وانتاج الموالح، وتم اختيار مفردات العينة من المزارعين بعينة الدراسة داخل القرية باستخدام المعاينة العشوائية العمدية. وقد أعتمدت الدراسة على البيانات المنشورة التى يصدرها

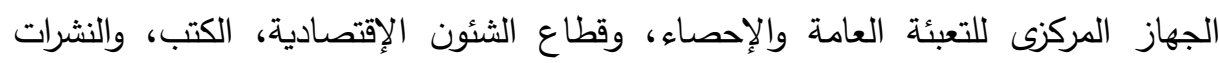

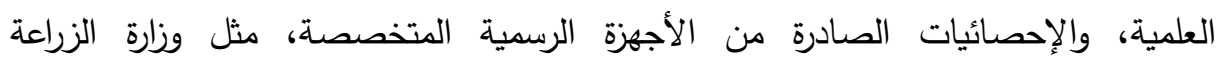
واستصلاح الأراضي، ومركز البحوث الزراعية، ومنظمة الأغذية والزراعة.

\section{المتهيار المينة المهنه}

تم اختيار عينة عمدية على مستوى المحافظة، ثم على مستوى المراكز، ثم على مستوى الحيازة داخل القربة وذلك بالخطوات التالية:

1) اختيار (المحافظة: اتضح من بيانات عام 9 ( ـ أن المساحة الكلية بالموالح بالمحافظة

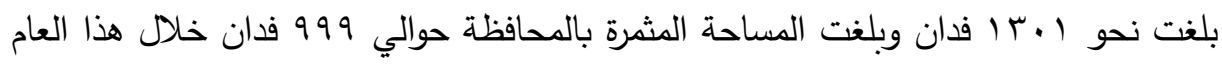

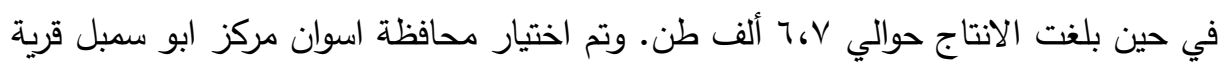

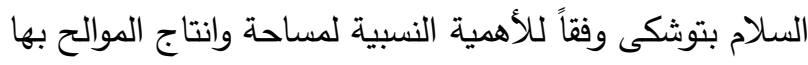
r) إختيار المركز: أما بالنسبة لاختيار المراكز فقد تم اختيارها طبقا للخطوات التالية:

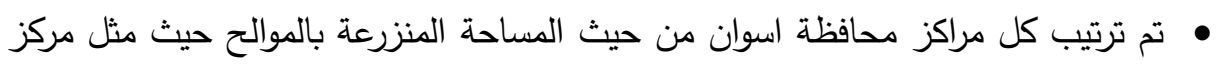

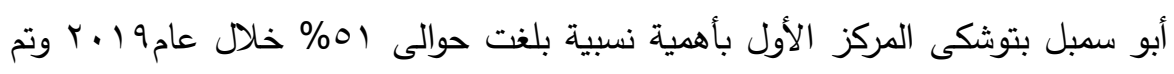

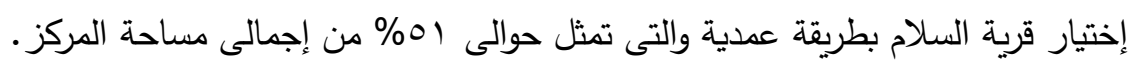

وتم اخذ (r • () مفردة من داخل القرية، تم تقسيمهم كالتالى:

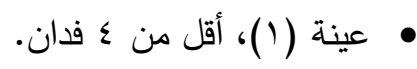
• • عينة (Y)، أقل من 1 ف فدان.

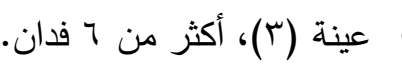




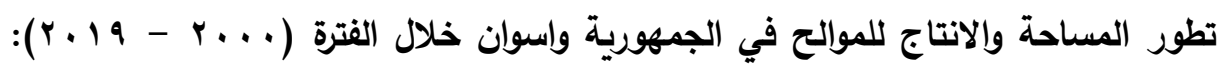
يستعرض هذا البحث الوضع الراهن لمحصول الموالح في مصر ومحافظة أسوان من حيث الجيث

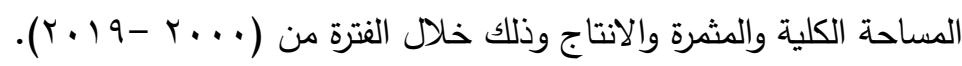
(1) المؤشرات الانتاجية لمحصول الموالج: يوضح الجدول رقم (1) المؤشرات الانتاجية

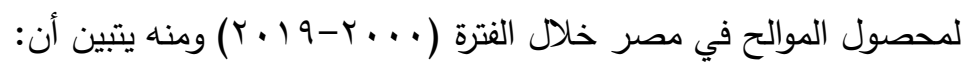
تطوي المساحة المنروعة الكلية من محصول المولتح: تثير الأرقام الواردة بالجدول رقم (1)

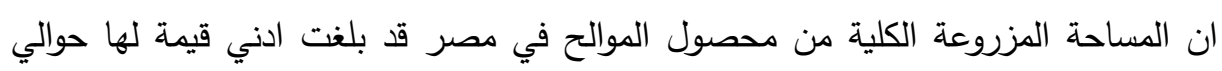

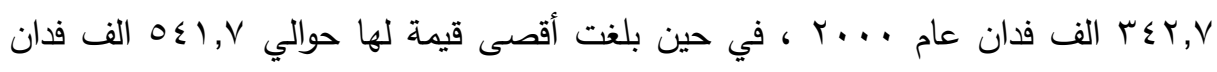

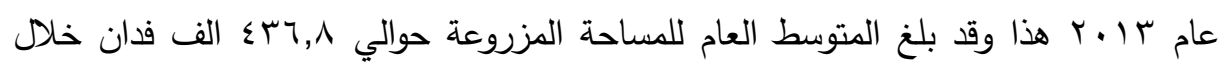

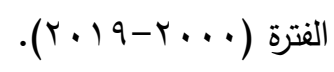

وتوضح المعادلة رقم (1) بالجدول رقم (Y) الاتجاه الزمني العام لتطور المساحة

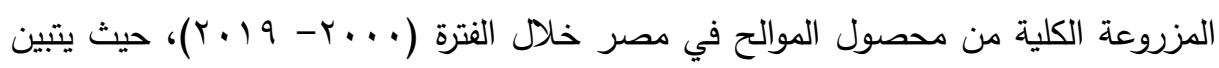

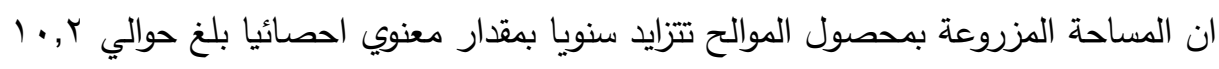

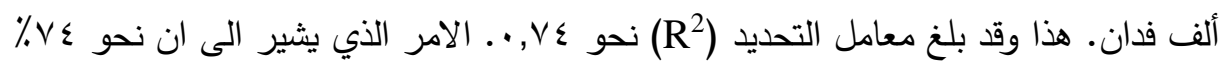
من التغيرات في المساحة المزروعة يعزي الي تغيرات يعكسها عامل الزمن.

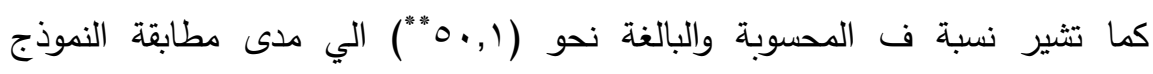
المستخدم لطبيعة البيانات موضع القياس.

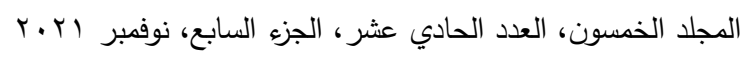

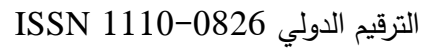

$$
\begin{aligned}
& \text { الترقيم الدولي الموحد الإكتروني 3178-2636 }
\end{aligned}
$$


مجلة العلوم البيئية

كلية الدراسات العليا والبحوث البيئية - جامعة عين شمس لبئه

ولاء عبد الجواد مصطفى وآخرون

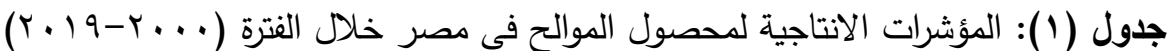

\begin{tabular}{|c|c|c|c|}
\hline الف طناج & المساحة المثمرة & المساحة الكلية & السنوات \\
\hline 2401.1 & 323.0 & 342.7 & 2000 \\
\hline 2594.9 & 322.3 & 344.8 & 2001 \\
\hline 2770.3 & 323.9 & 346.2 & 2002 \\
\hline 2748.3 & 325.7 & 352.8 & 2003 \\
\hline 2887.6 & 327.8 & 359.7 & 2004 \\
\hline 3030.2 & 332.8 & 364.8 & 2005 \\
\hline 3211.7 & 341.7 & 382.0 & 2006 \\
\hline 3134.2 & 344.4 & 394.5 & 2007 \\
\hline 3233.5 & 355.9 & 420.7 & 2008 \\
\hline 3510.9 & 368.3 & 451.5 & 2009 \\
\hline 3523.0 & 374.0 & 462.8 & 2010 \\
\hline 3730.7 & 395.7 & 483.3 & 2011 \\
\hline 3980.2 & 417.0 & 518.7 & 2012 \\
\hline 4098.6 & 439.0 & 541.7 & 2013 \\
\hline 4402.2 & 440.7 & 530.4 & 2014 \\
\hline 4646.6 & 449.6 & 533.8 & 2015 \\
\hline 4272.9 & 418.4 & 485.9 & 2016 \\
\hline 4451.6 & 444.3 & 477.5 & 2017 \\
\hline 4330.4 & 425.7 & 486.7 & 2018 \\
\hline 4245.7 & 414.6 & 456.1 & 2019 \\
\hline 3560.2 & 379.2 & 436.8 & المتوسط \\
\hline 2401.1 & 322.3 & 342.7 & الادني \\
\hline 4646.6 & 449.6 & 541.7 & الإعلى \\
\hline
\end{tabular}

المصدر: وزارة الزراعة واستصلاح الاراضي، قطاع الثئون الاقتصادية، نشرة المساحة المحصولية،

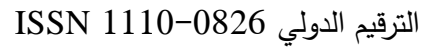

الترقيم الدولي الموحد الإكتروني 3178-2636 
جدول (ץ) : الاتجاه الزمنى العام لتطور المتغيرات لمحصول الموالح في مصر خلال الفترة

\begin{tabular}{|c|c|c|c|c|}
\hline \multicolumn{5}{|c|}{.$(r \cdot 19-r \ldots)$} \\
\hline $\mathbf{F}$ & $\mathbf{R}^{2}$ & معادلات الاتجاه الزمني العام & المتغيرات الانتاجية & المعادلة \\
\hline " 50.1 & 0.74 & $\begin{array}{c}\hat{Y}=329.30+10.2 X_{i} \\
(19.03) * *(7.7)^{* *}\end{array}$ & المساحة الكلية & 1 \\
\hline "110.5 & 0.86 & $\begin{array}{l}\hat{Y}=300.4+7.5 X_{i} \\
(35.1)^{* *}(10.5)^{* *}\end{array}$ & المساحة المثمرة & 2 \\
\hline$" 252.7$ & 0.93 & $\begin{array}{c}\hat{Y}=2350.5+115.2 X_{i} \\
(27.1)^{* * *}(15.9)^{* * *}\end{array}$ & الانتاج الكلي & 3 \\
\hline
\end{tabular}

المصدر: جمعت وحسبت من الأرقام الواردة بالجدول رقم (1)

حيث ان:

X: القيمة التقديرية للمتغيرات لمحصول الموالح في المشاهدة I أ. i متغير يعبر عن الزمن بالسنوات في المشاهدة ل: $\left.r . . . \ldots \ldots \ldots . . . .6 r_{6}\right)=i$

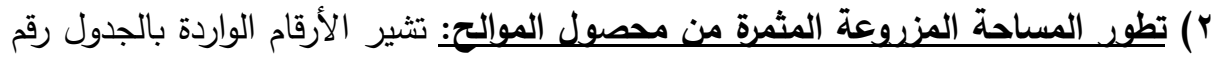

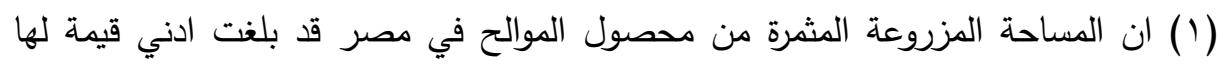

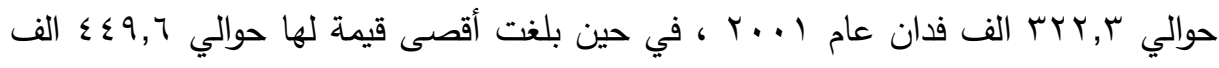

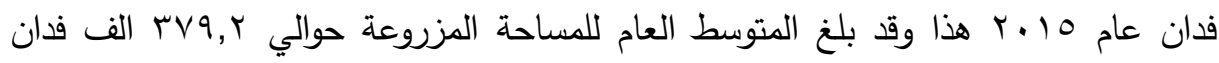

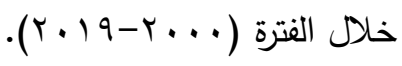

وتوضح المعادلة رقم (1) بالجدول رقم (Y) الاتجاه الزمني العام لتطور المساحة

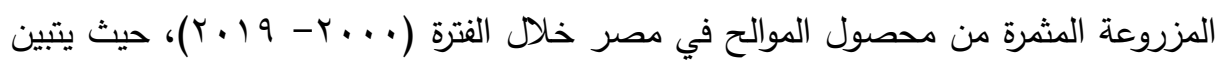

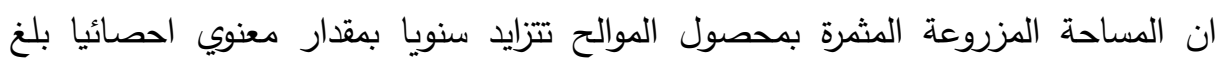

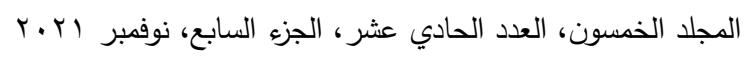

$$
\begin{aligned}
& \text { الترقيم الدولي 0826-0 الترني } \\
& \text { الترقيم الدولي الموحد الإكتروني 3178-2636 }
\end{aligned}
$$




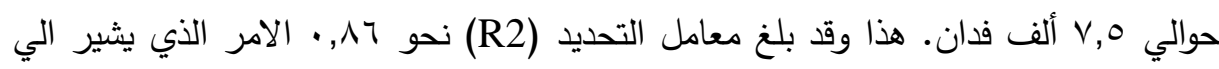
ان نحو \^٪ من التغيرات في المساحة المزروعة يعزي الي تغيرات يعكسها عامل الزمن.

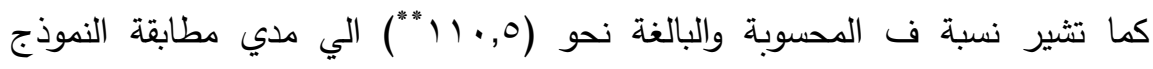
المستخدم لطبيعة البيانات موضع القياس (خليل، 997 (1) ).

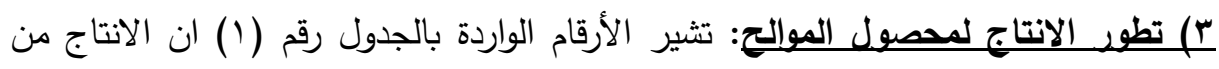

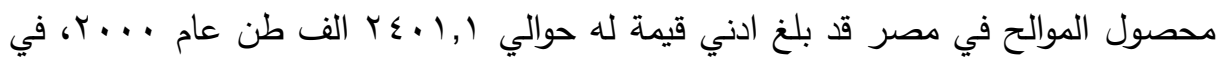

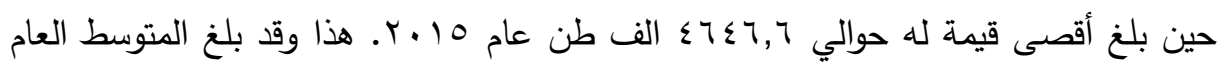

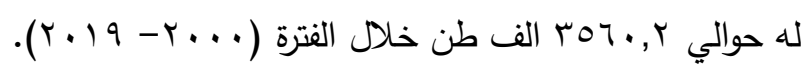

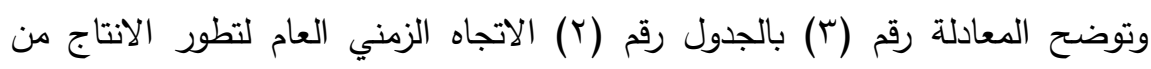

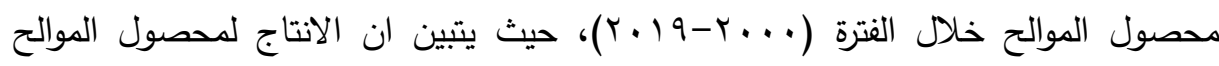

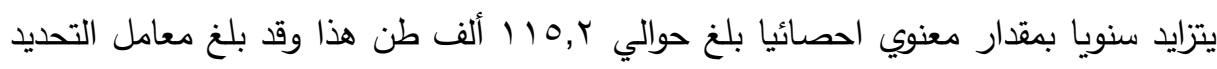
(R²)

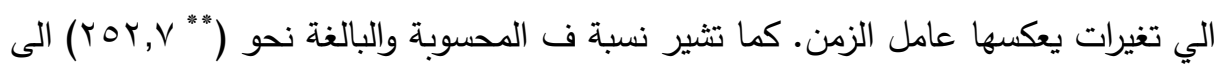

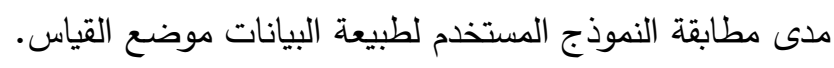

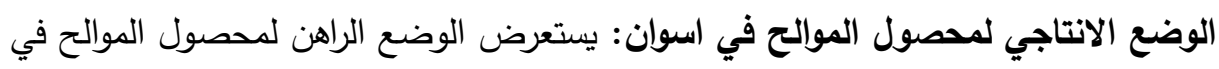

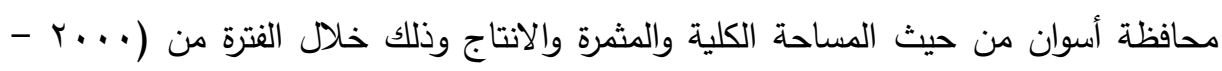
.$(Y \cdot 19$

() المؤشرات الانتاجية لمحصول الموالح في محافظة أسوان: يوضح الجدول رقم (r)

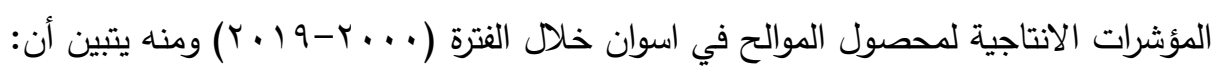

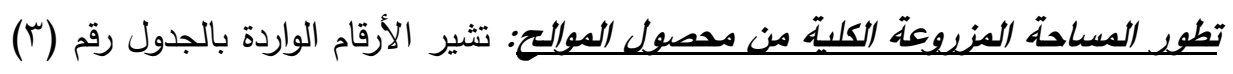
ان المساحة المزروعة الكلية من محصول الموالح في اسوان قد بلغت ادنى قيمة لها حوالي

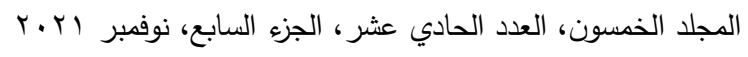

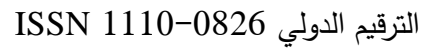

$$
\begin{aligned}
& \text { الترقيم الدولي الموحد الإلكتروني 3178-2636 الترول }
\end{aligned}
$$




\section{مجلة العلوم البيئية \\ كلية الدراسات العليا والبحوث البيئية - جامعة عين شمس لائة \\ ولاء عبد الجواد مصطفى وآخرون}

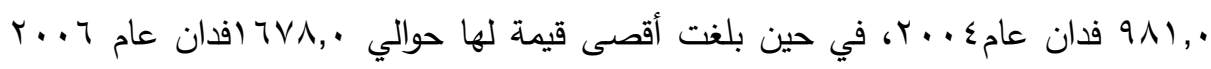

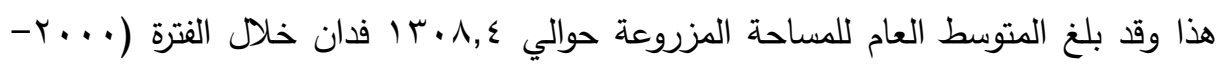

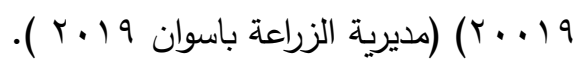

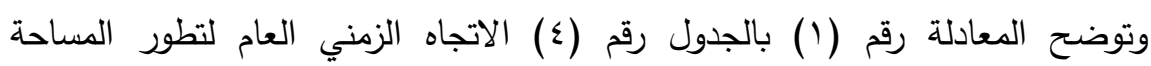

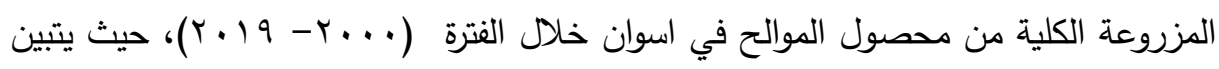

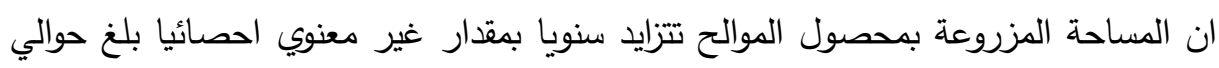

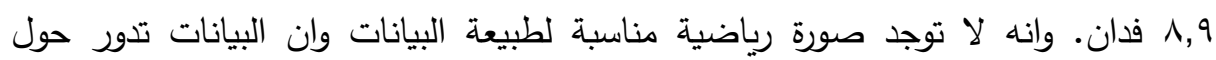
متوسطها الحسابي (وزارة الزراعة واستصلاح الاراضي أعداد متفرقة) .

$$
\begin{aligned}
& \text { المجلد الخمسون، العدد الحادي عشر ، الجزء السابع، نوفمبر إr.r } \\
& \text { الترقيم الدولي 0826-0 التئ } \\
& \text { الترقيم الدولي الموحد الإكتروني 3178-2636 }
\end{aligned}
$$


مجلة العلوم البيئية

كلية الدراسات العليا والبحوث البيئية - جامعة عين شمس لبئه

ولاء عبد الجواد مصطفى وآخرون

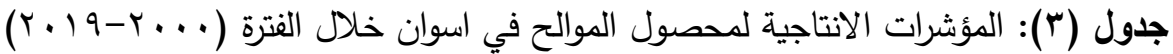

\begin{tabular}{|c|c|c|c|}
\hline الانتاج & فالماحة المثمرة & فالماحة الكلية & السنوات \\
\hline 8426 & 988 & 1077 & 2000 \\
\hline 8745 & 1017 & 1099 & 2001 \\
\hline 10599 & 1010 & 1106 & 2002 \\
\hline 8370 & 985 & 1094 & 2003 \\
\hline 7318 & 834 & 981 & 2004 \\
\hline 6917 & 762 & 1548 & 2005 \\
\hline 7869 & 833 & 1678 & 2006 \\
\hline 8609 & 890 & 1386 & 2007 \\
\hline 9380 & 961 & 1573 & 2008 \\
\hline 8617 & 867 & 1210 & 2009 \\
\hline 11523 & 1182 & 1306 & 2010 \\
\hline 10380 & 1064 & 1469 & 2011 \\
\hline 10084 & 1048 & 1505 & 2012 \\
\hline 8643 & 1041 & 1359 & 2013 \\
\hline 10000 & 1061 & 1359 & 2014 \\
\hline 11248 & 1063 & 1381 & 2015 \\
\hline 14195 & 1198 & 1209 & 2016 \\
\hline 12556 & 1203 & 1226 & 2017 \\
\hline 10290 & 995 & 1301 & 2018 \\
\hline 6673 & 999 & 1301 & 2019 \\
\hline 9522.1 & 1000.1 & 1308.4 & المتوسط \\
\hline 6673.0 & 762.0 & 981.0 & الحد الادنى \\
\hline 14195.0 & 1203.0 & 1678.0 & الحد الاعلى \\
\hline
\end{tabular}

المصدر: وزارة الزراعة واستصلاح الاراضي، قطاع الثئون الاقتصادية، نشرة المساحة المحصولية،

أعداد متفرقة.

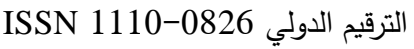

الترقيم الدولي الموحد الإكتروني 3178-2636 
جدول (؛): الاتجاه الزمنى العام لتطور المتغيرات لمحصول الموالح في اسوان خلال الفترة

\begin{tabular}{|c|c|c|c|c|}
\hline $\mathbf{F}$ & R2 & معادلات الاتجاه الزمني العام & 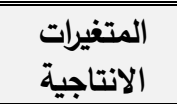 & 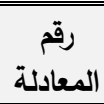 \\
\hline 1.6 & 0.08 & $\begin{aligned} \hat{Y}= & 1215.01+8.9 X_{i} \\
& (14.2)^{* * *}(1.2)\end{aligned}$ & الكلية (فدانة) & 1 \\
\hline " 7.6 & 0.58 & $\begin{aligned} \hat{\mathbf{Y}=} & 1171.5-120.7 \mathrm{Xi}+14.3 \mathrm{Xi}^{2}-0.44 \mathrm{X}^{3} \mathbf{i} \\
& (12.7)^{* *}(-3.3)^{* * *}(3.5)^{* * *}(-3.4)^{* * *}\end{aligned}$ & المثرة (فدانة) & 2 \\
\hline " 4.2 & 0.44 & $\begin{array}{c}\hat{\mathbf{Y}}=11042.5-1459.2 \mathrm{Xi}+191.3 \mathrm{Xi}^{2}-6.2 \\
\mathrm{X}^{3} \mathbf{i} \\
(6.5)^{* *}(-2.1)^{* *}(2.6)^{* *}(-2.6)^{* *}\end{array}$ & الانتاج الكلي & 3 \\
\hline
\end{tabular}

المصدر: جمعت وحسبت من الأرقام الواردة بالجدول رقم (r) حيث ان: X: القيمة التقديرية للمتغيرات لمحصول الموالح في المشاهدة I ا . i متغير يعبر عن الزمن بالسنوات في المشاهدة: Xi r..............6 $\left.r_{6}\right)=i$

تظوف المساحة المندوعة المثمرة من محصول الموالج: تثير الأرقام الواردة بالجدول رقم (r) ان المساحة المزروعة المثرة من محصول الموالح في اسوان قد بلغت ادني قيمة لها لهابل

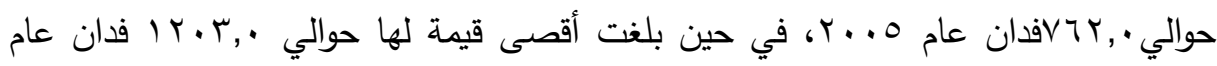

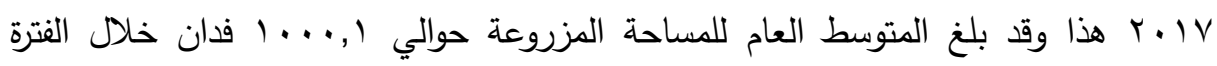

$$
\cdot(r \cdot 19-r \cdot \cdots)
$$

وتوضح المعادلة رقم (ץ) بالجدول رقم (ع) الاتجاه الزمني العام لتطور المساحة

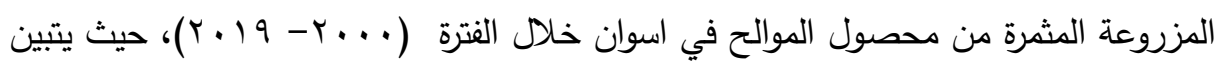

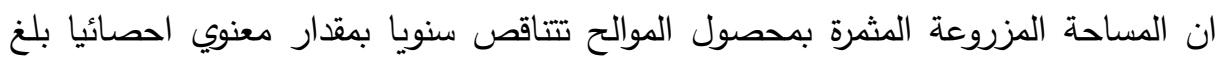

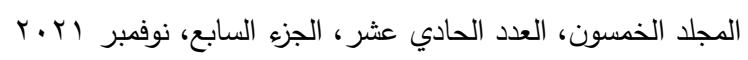

$$
\begin{aligned}
& \text { الترقيم الدولي 0826-0 1110 } \\
& \text { الترقيم الدولي الموحد الإلكتروني 3178-0826-2636 }
\end{aligned}
$$




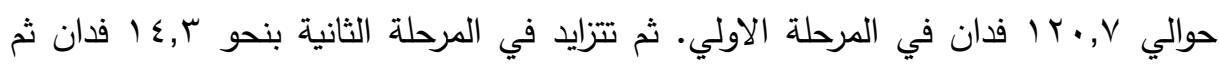

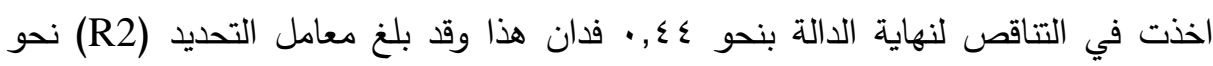

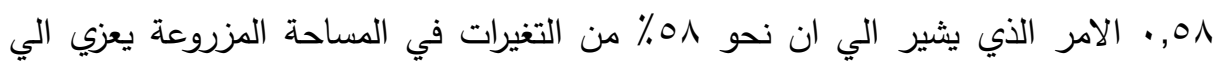
تغيرات يعكسها عامل الزمن.

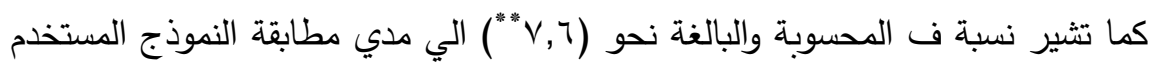
لطبيعة البيانات موضع القياس. تظور الاتتاج لمحصول الموالج: تثير الأرقام الواردة بالجدول رقم (r) ان الانتاج من

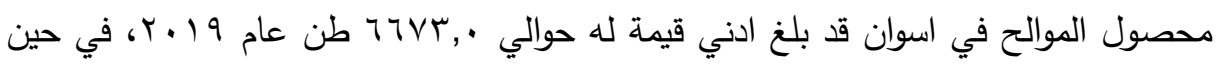

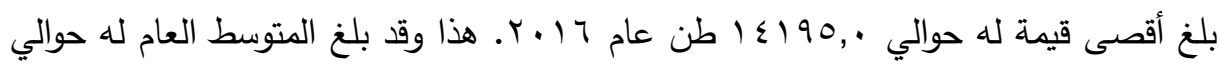

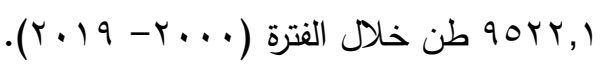
وتوضح المعادلة رقم (ץ) بالجدول رقم (ع) الاتجاه الزمني العام لتطور الانتاج من

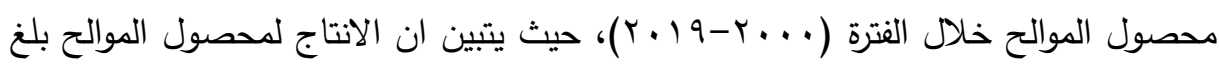

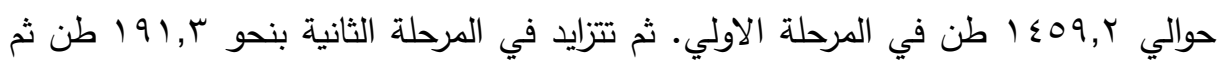

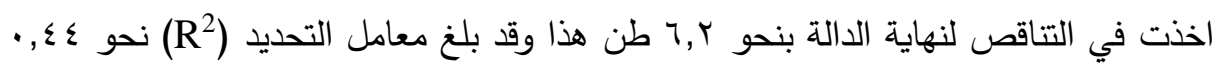

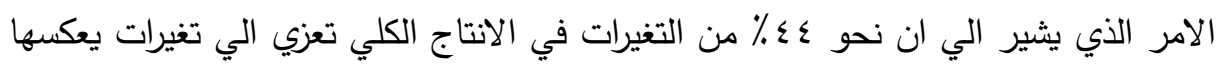

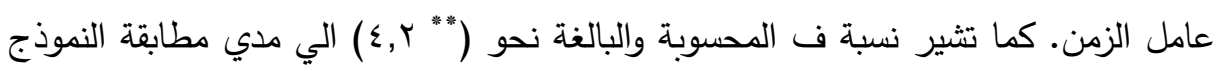
المستخدم لطبيعة البيانات موضع القياس. دالة إنتاج محصول الموالح علي مستوي إجمالي عينة الدراسة: تم تقدير معالم الدالة الإنتاجية لمحصول الموالح من بيانات عينة الدراسة وفقاً للنموذج المقدر في صورة (كوب - دوجلاس) المحول إلى الصورة اللوغاريتمية المزدوجة لتبسيط تقدير مشتقات الدالة

$$
\begin{aligned}
& \text { المجلد الخمسون، العدد الحادي عشر ، الجزء السابع، نوفمبر اYr.r } \\
& \text { الترقيم الدولي 0826-08S 1110 تصني } \\
& \text { الترقيم الدولي الموحد الإكتروني 3178-2636 }
\end{aligned}
$$


وسهولة تفيرها، بإدخال جميع العناصر الإنتاجية المؤثرة على الناتج الكلي للفدان من خلال

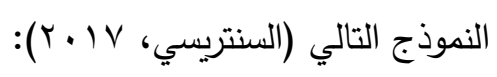
$\ln Q=\ln \alpha+\beta_{1} \ln X_{1}+\beta_{2} \ln X_{2}+\beta_{3} \ln X_{3}+\ldots . .+\beta_{7} \ln X_{7}$ حيث :

= = Q

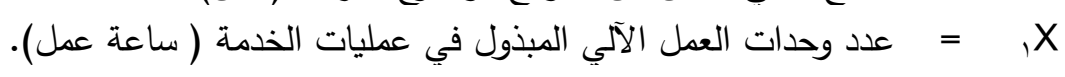

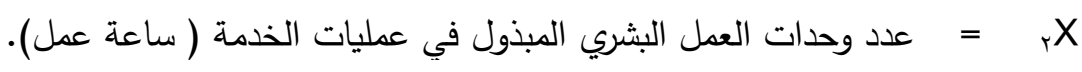

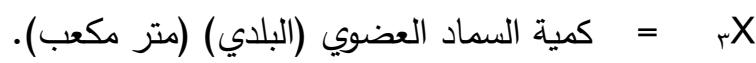
= $=X_{4}$ كمية السماد الفوسفاتي (وحدة فعالة). : $=X_{6}$ ك = $=X_{7}$ = B

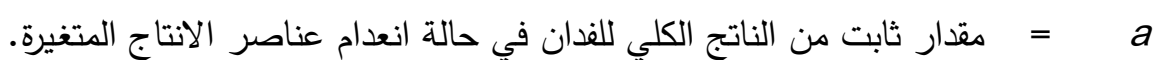

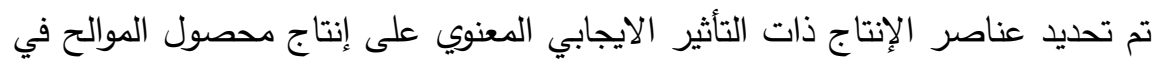

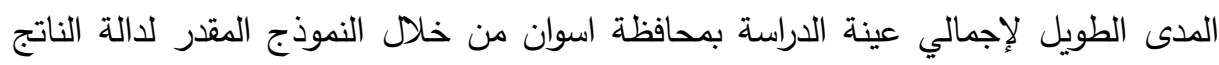

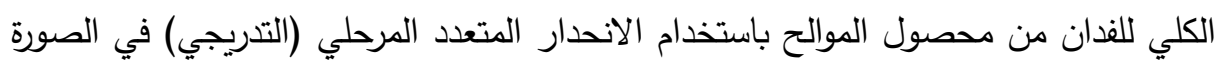

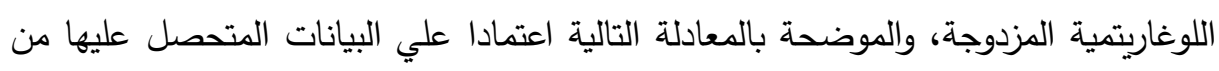

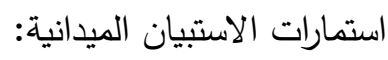

$\operatorname{Ln} \mathrm{Q}=\cdot, 11 \operatorname{Ln} \mathrm{X} 2+\cdot,$, ○ $\operatorname{Ln} \mathrm{X} 3+\cdot, \mathrm{r} \wedge \operatorname{Ln} \mathrm{X} 4$
$(0,7)$
$(7, Y) * *$

$\overline{\mathrm{R}}^{2}=$

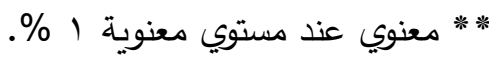

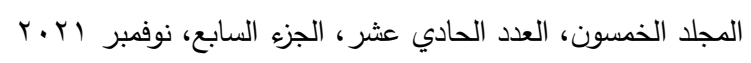

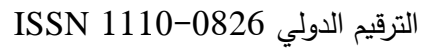

الترقيم الدولي الموحد الإكتروني 3178-0826-2636 
حيث تبين من دالة الناتج الكلي (Q) أن أهم العناصر الانتاجية ذات التأثير المعنوي

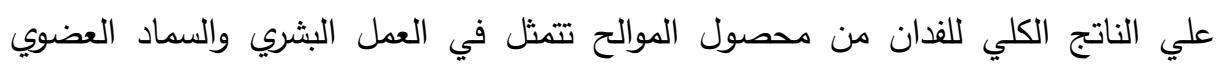
والسماد الازوتي وبتقدير مرونات الإنتاج الجزئية المختلفة لتلك العناصر، تبئ لتين أن المرونة

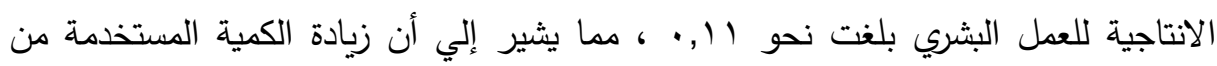

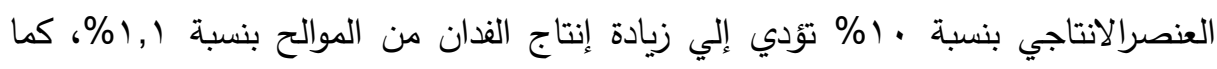

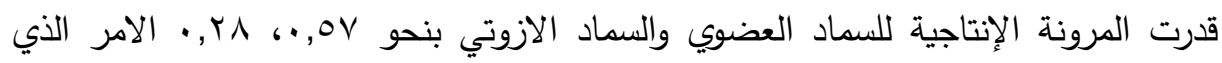

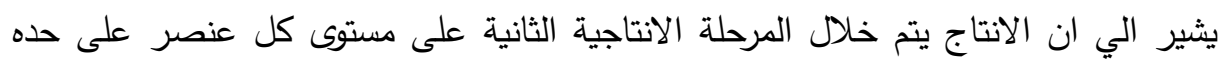

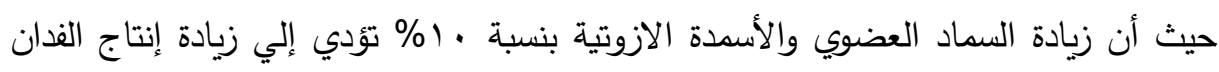

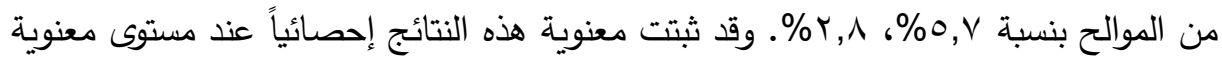
$\cdot(\cdot, \cdot 1)$

أما على مستوى عناصر الانتاج مجتمعة فقد قدرت المرونة الانتاجية الإجمالية (E.P.)

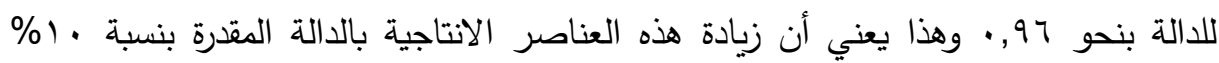

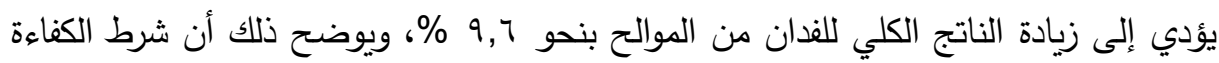

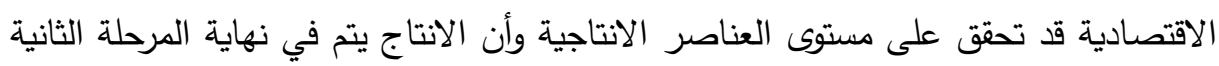

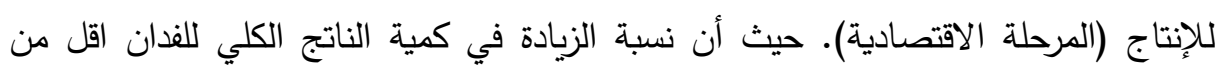
نسبة الزيادة في كمية عناصر الانتاج المستخدمة أي ما يعني تتاقص العائد للسعة.

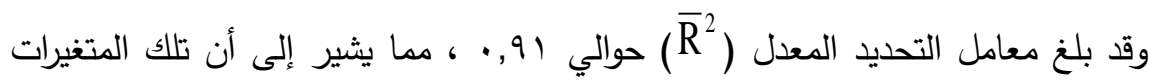

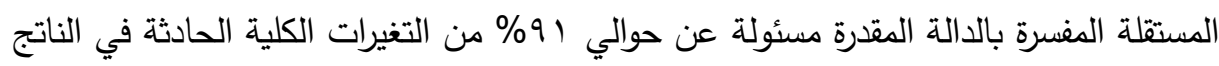
الكلي للفدان من محصول الموالح ، وتثير قيمة (F) إلى المعنوية الإحصائية للدالة المقدرة عند مستوى معنوية (1 (., (•). 
وتم اشتقاق الناتج الحدي والناتج المتوسط بالنسبة لكل عنصر إنتاجي في دالة الناتج الكلي المقدرة لمحصول الموالح لإجمالي عينة الدراسة، حيث تبين من جدول (1) أن الناتج

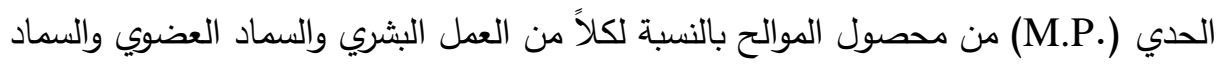

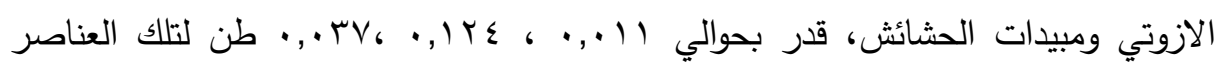
الانتاجية على الترتيب، كما قدرت قيمة الناتج الحدي (V.M.P) لتلك العناصر الانتاجية

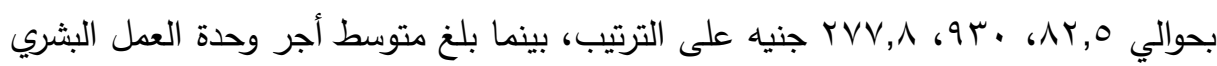

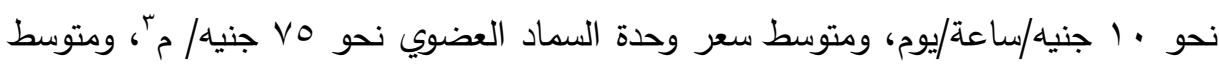

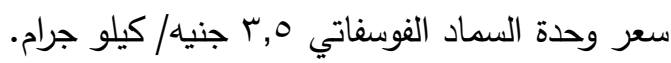

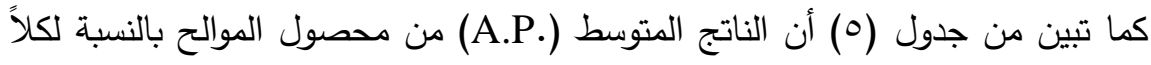

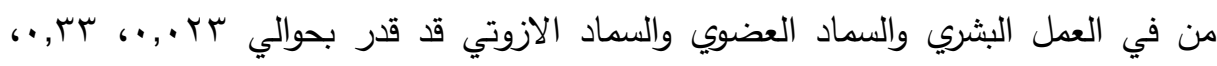
جr ا, • طن لتلك العناصر الانتاجية على الترتيب.

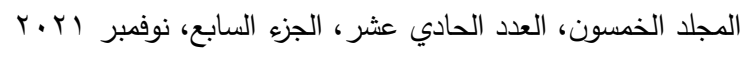

$$
\begin{aligned}
& \text { الترقيم الدولي 0826-0 الترني } \\
& \text { الترقيم الدولي الموحد الإكتروني 3178-2636 }
\end{aligned}
$$


جدول (•): مؤشرات الكفاءة الاقتصادية لاستخدام عناصر الإنتاج المستخدمة في دالة انتاج

الموالح بإجمالي عينة الدراسة

\begin{tabular}{|c|c|c|c|}
\hline \multicolumn{3}{|c|}{ عناصر الانتاج (المدخلات) في دالة الناتج الكلي } & \multirow{3}{*}{ البيان } \\
\hline السماد الازوتي & السماد العضوي & العمل البشري & \\
\hline$X_{4}$ & $x_{3}$ & $x_{2}$ & \\
\hline$r \wedge 0,7$ & $1 \cdot v, 0$ & $10 r 9,0$ & Dتوسط كمية عنصر الانتاج \\
\hline \multicolumn{3}{|c|}{36.26} & متوسط الناتج الكلي Q (طن) \\
\hline$\cdot, Y \wedge$ & $\cdot$, OV & $\cdot, 11$ & المرونة الانتاجية لعنصر الانتاج (E.X.) \\
\hline \multicolumn{3}{|c|}{$\cdot, 97$} & المرونة الانتاجية الإجمالية (E.P.) \\
\hline$\cdot$ & • & 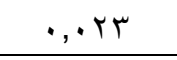 & الناتج المتوسط (A.P.) (طن) \\
\hline$\cdot, \cdot r V$ & $\cdot, 1 Y \varepsilon$ & $\cdot, .+11$ & الناتج الحدي (M.P.P) (طن) \\
\hline$Y V V, \Lambda$ & $9 r$. & $\Lambda Y, 0$ & قيمة الناتج الددي (V.M.P.) (جنيه) \\
\hline$r, 0$ & vo & 1. & سعر وحدة عنصر الانتاج (Px) (جنيه) \\
\hline$\vee q, r$ & $M, \varepsilon$ & $\Lambda, r$ & الكفاءة الاقتصادية (E.E.) \\
\hline
\end{tabular}

المصدر : جمعت وحسبت من نتائج الاستبيان الخاص بالدراسة

* سعر وحدة الناتج الرئيسي (متوسط سعر طن الموالح) = . . عنيها ل

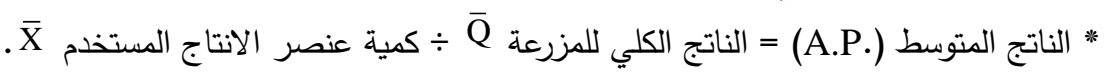

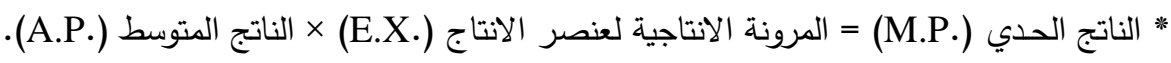

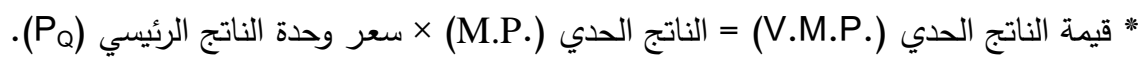

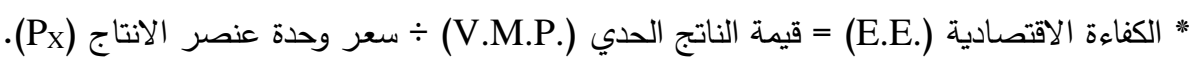
وتم تقدير الكفاءة الاقتصادية لاستخدام العناصر الانتاجية بدالة الناتج الكلي المقدرة،

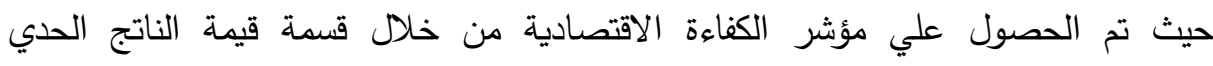
لكل عنصر إنتاجي على سعر وحدة هذا العنصر الإنتاجي(P.M.P)

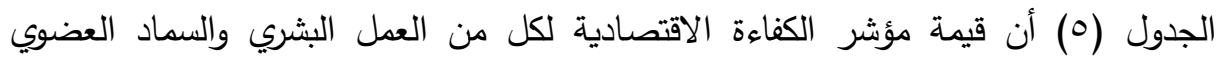
558

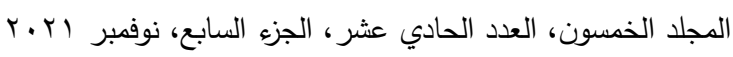

$$
\begin{aligned}
& \text { الترقيم الدولي 0826-08S 1110 } \\
& \text { الترقيم الدولي الموحد الإلكتروني 3178-0826-2636 }
\end{aligned}
$$


والسماد الفوسفاتي أكبر من الواحد الصحيح مما يشير إلى ارتفاع مستوى الكفاءة الاقتصادية

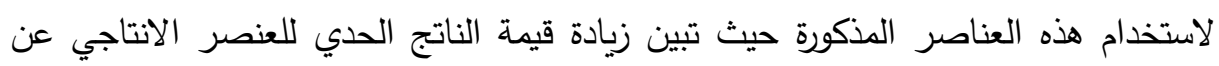
سعر وحدة العنصر الانتاجي. دالة إنتاج الموالح للفئة الحيازية الأولي (أقل من أربع فدان): تم تحديد عناصر الإنتاج ذات التأثير الايجابي المعنوي على إنتاج محصول الموالح في المدى القصير للفئة

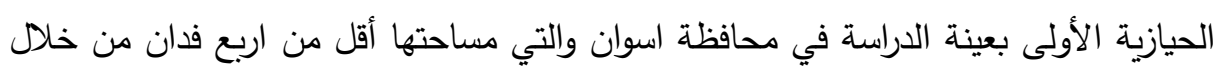

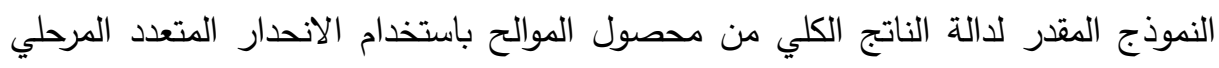

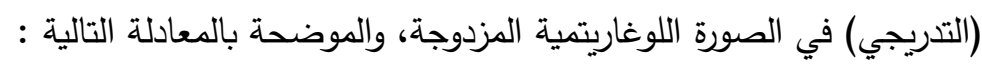
$\operatorname{LnQ}=r . \bullet+\cdot, 7 r 9 \operatorname{Ln} X 2+\cdot, 0 r r \operatorname{Ln} X 3$

$$
\overline{\mathrm{R}}^{2}=\quad \begin{gathered}
(\xi, \Gamma)^{* *}(\xi, \vee)^{* * *} \quad(r, \varepsilon) * * \\
\cdot, \wedge \wedge F=1 r \mu, \vee
\end{gathered}
$$

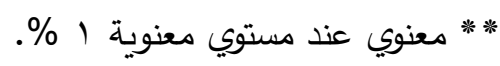

حيث تبين من دالة الناتج الكلي (Q) أن أهم العناصر الانتاجية ذات التأثير المعنوي

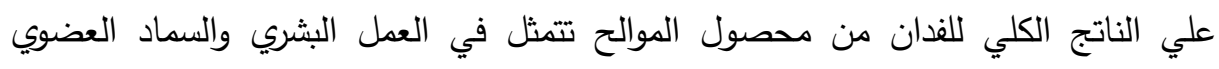

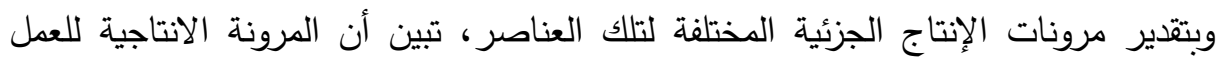

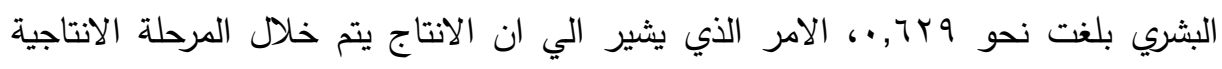

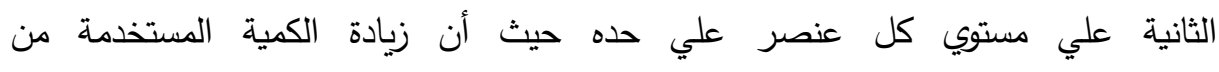

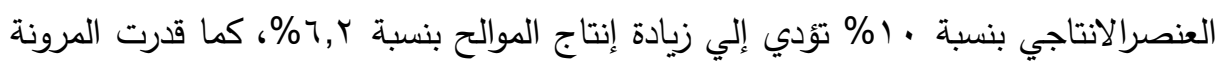

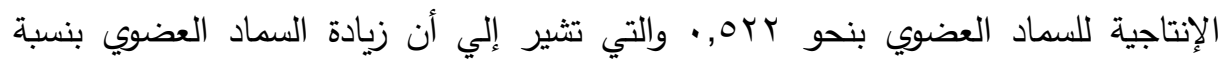

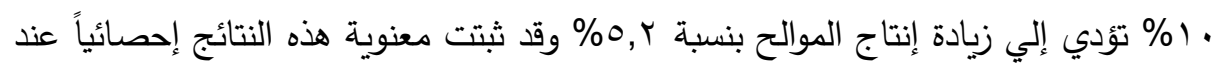

$$
\text { مستوى معنوية (1 ( +. (·). }
$$

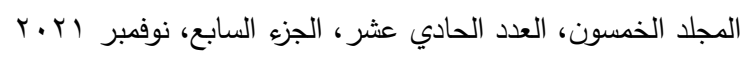

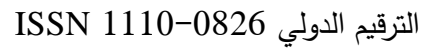

$$
\begin{aligned}
& \text { الترقيم الدولي الموحد الإكتروني 3178-2636 }
\end{aligned}
$$


اما علي مستوي عناصر الانتاج مجتمعة فقد قدرت المرونة الانتاجية الإجمالية (E.P.)

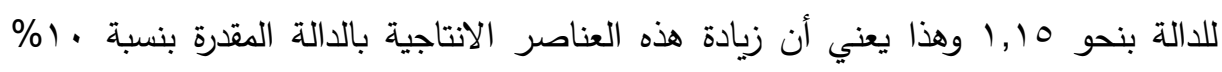

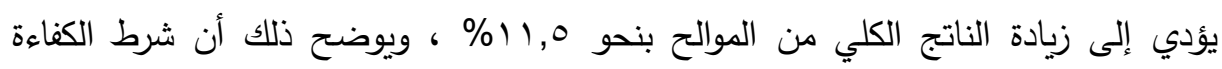

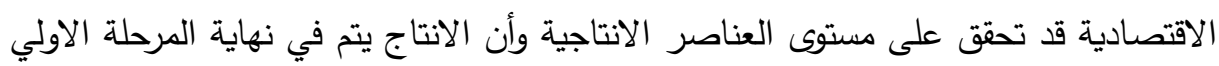

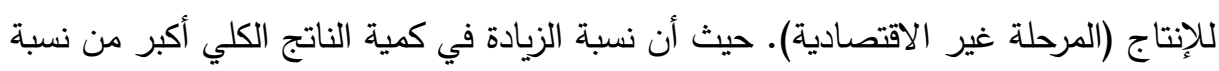
الزيادة في كمية عناصر الانتاج المستخدمة أي ما يعني زيادة العائد للسعة.

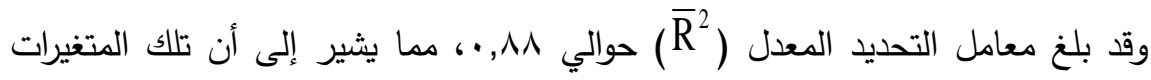

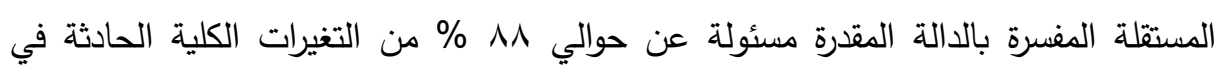
الناتج الكلي من محصول الموالح، وتثير قيمة (F) إلى المعنوية الإحصائية للدالة المقدرة عند الدئل

$$
\text { مستوى معنوية (1 + • •). }
$$

وتم تقدير الناتج الحدي والناتج المتوسط بالنسبة لكل عنصر إنتاجي في دالة الناتج الكلي

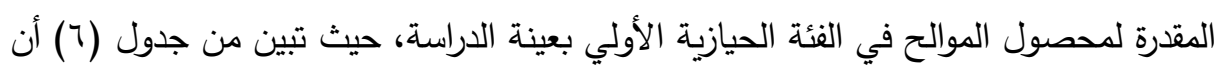

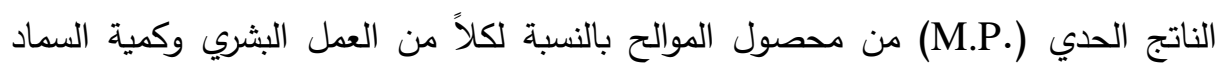

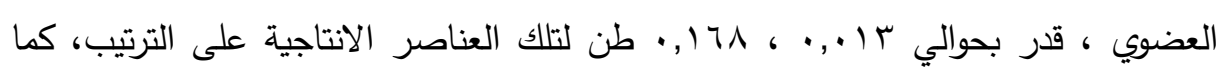

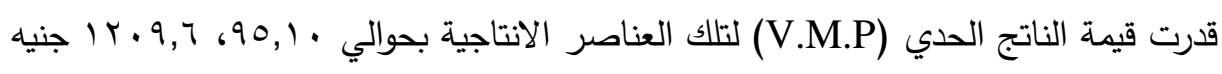

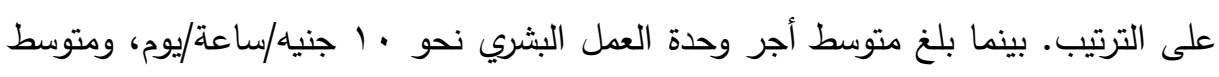

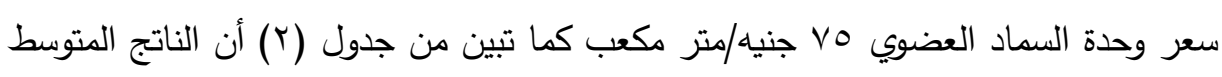
(A.P.)

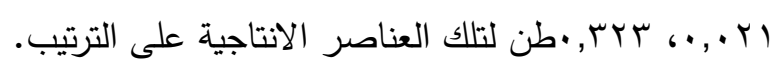
وتم اشتقاق الكفاءة الاقتصادية لاستخدام العناصر الانتاجية بدالة الناتج الكلي المقدرة، لكاهيه

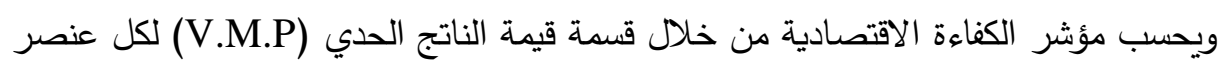

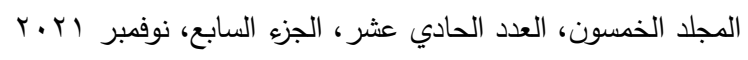

$$
\begin{aligned}
& \text { الترقيم الدولي التي التوني } \\
& \text { الترقيم الدولي الموحد الإكتروني 3178-2636 }
\end{aligned}
$$


إنتاجي على سعر وحدة هذا العنصر الإنتاجي(Px)، حيث تبين من الجدول (7) أن قيمة مؤشر الكفاءة الاقتصادية لكل من العمل البشري والسماد العضوي أكبر من الواحد الصحيح مما يثير إلى ارتفاع مستوى الكفاءة الاقتصادية لاستخدام هذه العناصر المذكورة حيث تبين زيادة قيمة الناتج الحدي للعنصر الانتاجي عن سعر وحدة العنصر الانتاجي، وينصح

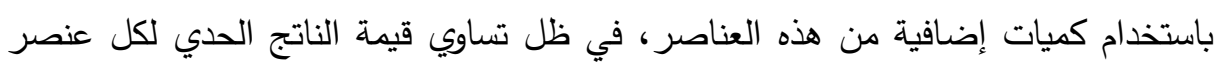
إنتاجي مع سعر الوحدة من هذا العنصر الإنتاجي. جدول (†): مؤشرات الكفاءة الاقتصادية لاستخدام عناصر الإنتاج المستخدمة في دالة انتاج

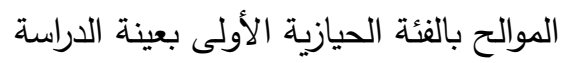

\begin{tabular}{|c|c|c|}
\hline \multicolumn{2}{|c|}{ فناصر الانتاج (المدخلات) } & \multirow{3}{*}{ 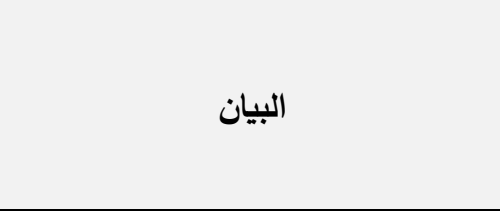 } \\
\hline السماد العضوي & العمل البشري & \\
\hline $\mathrm{X}_{3}$ & $\mathrm{X}_{1}$ & \\
\hline$\leq 7,9$ & Nor,l & متوسط كمية عنصر الانتاج \\
\hline \multicolumn{2}{|c|}{10,10} & متوسط الناتج الكلي Q (طن) \\
\hline.,$O Y Y$ & $\cdot, 7 \times 9$ & المرونة الانتاجية لعنصر الانتاج (E.X.) \\
\hline \multicolumn{2}{|c|}{1,10} & المرونة الانتاجية الإجمالية (E.P.) \\
\hline 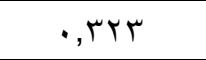 & $\cdot, \cdot r_{1}$ & الناتج المتوسط (A.P.) (طن) \\
\hline$\cdot, 171$ & $\cdot, .14$ & الناتج الحدي (M.P.) (طن) \\
\hline $1 r \cdot 9,7$ & $90,1$. & قيمة الناتج الحدي (V.M.P.) (جنيه) \\
\hline vo & 1. & سعر وحدة عنصر الانتاج (Px) (جنيه) \\
\hline 17,11 & 9,0 & الكفاءة الاقتصادية (E.E.) \\
\hline
\end{tabular}

المصدر: جمعت وحسبت من نتائج الاستبيان الخاص بالدراسة .

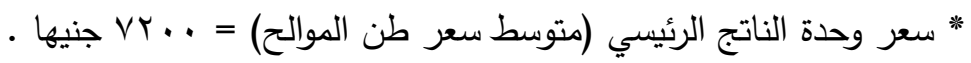


دالة إنتاج الموالح للفئة الحيازية الثانية (من ؛ الي 7 فدان): تم تحديد عناصر

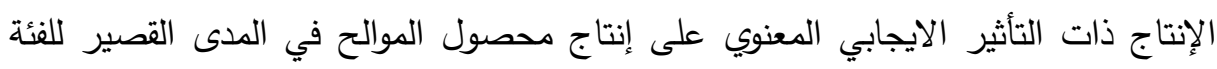

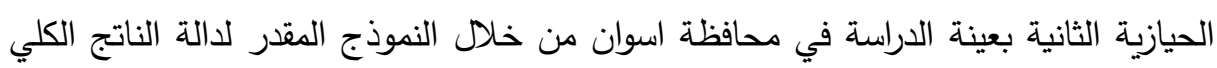

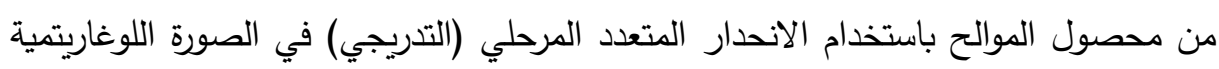

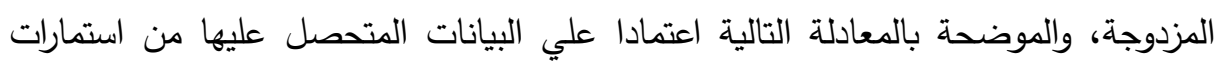
$\operatorname{Ln} \mathrm{Q}=\cdot, 10+\cdot, \wedge 1 \operatorname{Ln} \mathrm{X} 6+\cdot, 1 \wedge \mathrm{Ln} \mathrm{X} 7$

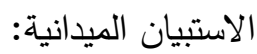
$(r, 70) * *(\uparrow, 0 \xi)^{* *} \quad(r, 0 \tau) *$ $\overline{\mathrm{R}}^{2}=$ $\cdot, 9 \cdot F=70,9$

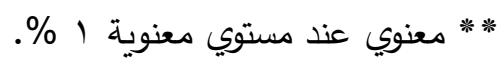

حيث تبين من دالة الناتج الكلي (Q) أن أهم العناصر الانتاجية ذات التأثير المعنوي

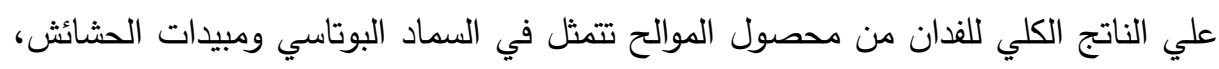

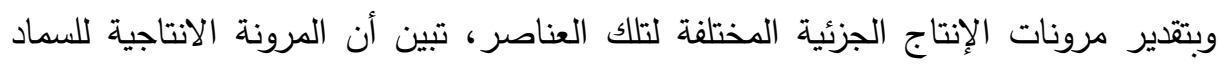

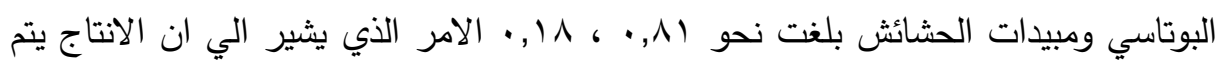

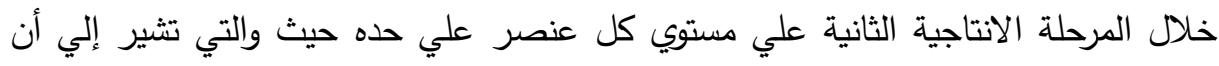

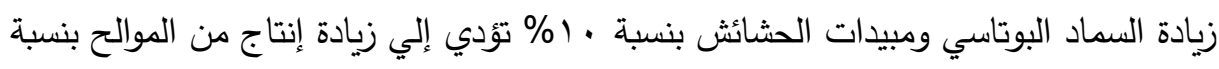

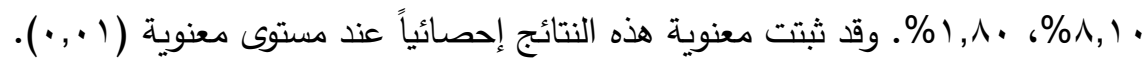

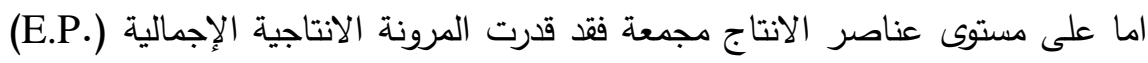

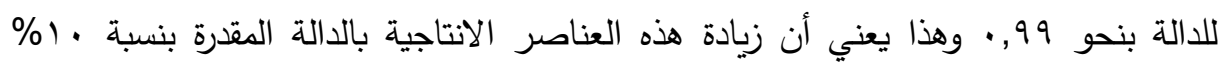

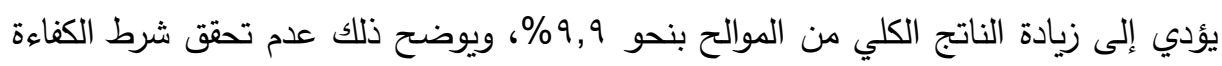
الاقتصادية قد تحقق على مستوى العناصر الانتاجية وأن الانتاج يتم في بداية الكانع المرحلة الثانية

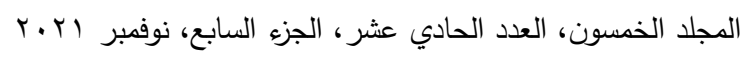

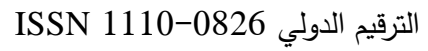

$$
\begin{aligned}
& \text { الترقيم الدولي الموحد الإكتروني 3178-2636 }
\end{aligned}
$$


للإنتاج (المرحلة الاقتصادية). حيث أن نسبة الزيادة في كمية الناتج الكلي اقل من نسبة

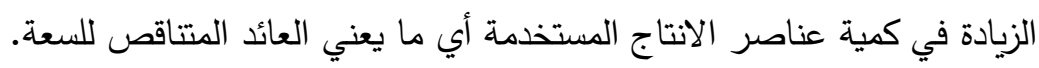

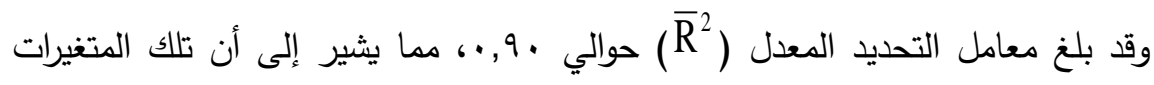
المستقلة المفسرة بالدالة المقدرة مسئولة عن حوالي ، 9\% من التغيرات الكلية الحادثة في الناتج

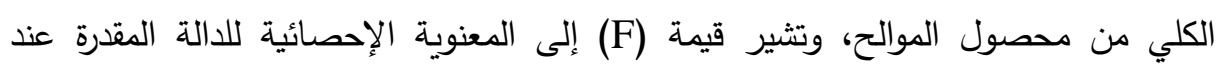
مستوى معنوية (1 •. •). وتم تقدير الناتج الحدي والناتج المتوسط بالنسبة لكل عنصر إنتاجي في دالة الناتج الكلي

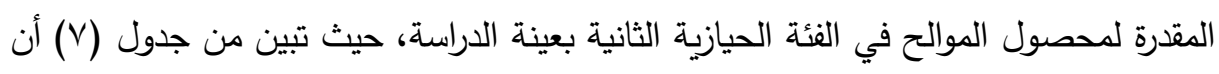

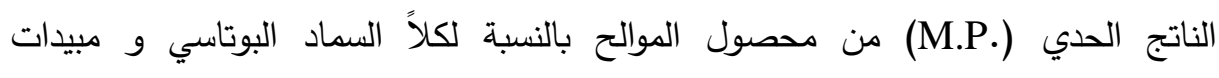

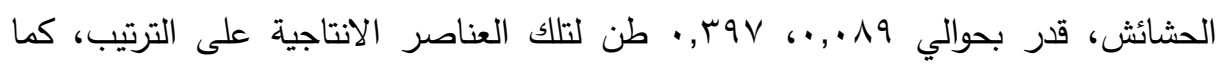

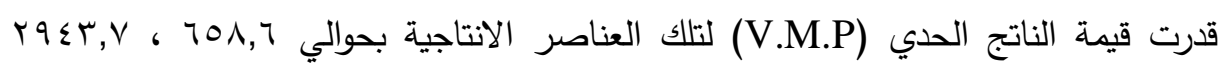

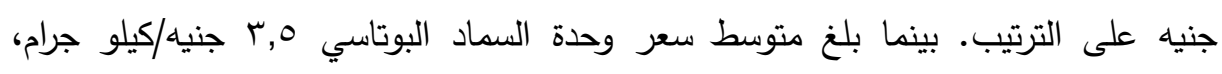
ومتوسط سعر وحدة مبيدات الحشائش نحو 170 جنئه

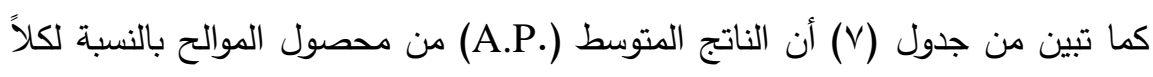

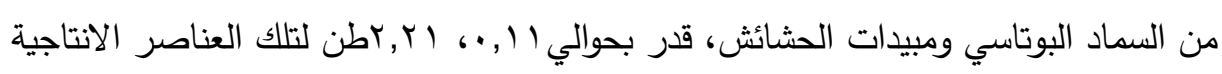
على الترتيب.

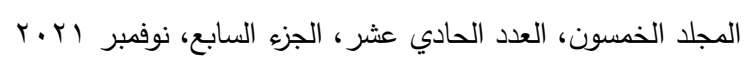

$$
\begin{aligned}
& \text { الترقيم الدولي التي التوني } \\
& \text { الترقيم الدولي الموحد الإكتروني 3178-2636 }
\end{aligned}
$$


جدول (V): مؤشرات الكفاءة الاقتصادية لاستخدام عناصر الإنتاج المستخدمة في دالة انتاج الموالح بالفئة الحيازية الثانية بعينة الدراسة

\begin{tabular}{|c|c|c|}
\hline \multicolumn{2}{|c|}{ عناصر الانتاج (المدخلات) في دالة الناتج الكلي } & \multirow{3}{*}{ 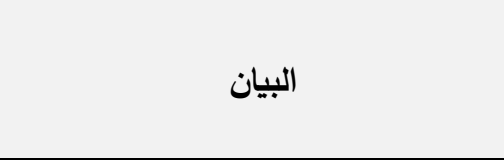 } \\
\hline مبيدات الحشائش & السماد البوتاسي & \\
\hline$X_{7}$ & $X_{4}$ & \\
\hline $1 \Lambda, Y V$ & rیr,. 9 & Dتوسط كمية عنصر الانتاج \\
\hline \multicolumn{2}{|c|}{$\varepsilon \cdot, \leqslant 0$} & متوسط الناتج الكلي Q (طن) \\
\hline$\cdot, 1 \wedge$ & $\cdot, \wedge)$ & المرونة الانتاجية لعنصر الانتاج (E.X.) \\
\hline \multicolumn{2}{|c|}{$\cdot, 99$} & المرونة الاتتاجية الإجمالية (E.P.) \\
\hline$r, r_{1}$ & $\cdot, 11$ & الناتج المتوسط (A.P.) (طن) \\
\hline$\cdot$, r ४ & $\cdot, \cdot 19$ & الناتج الحدي (M.P.) (طن) \\
\hline$r q \leqslant r, V$ & 701,7 & قيمة الناتج الحدي (V.M.P.) (جنيه) \\
\hline 170 & $r, 0$ & سعر وحدة عنصر الانتاج (PXX) (جنيه) \\
\hline $\mid V, \wedge \varepsilon$ & $1 \wedge \Lambda, 1 \vee$ & الكفاءة الاقتصادية (E.E.) \\
\hline
\end{tabular}

المصدر: جمعت وحسبت من نتائج الاستبيان الخاص بالدراسة .

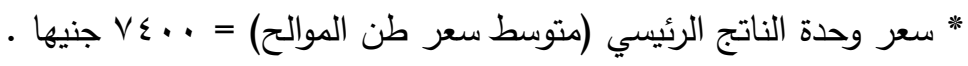
وتم تقدير الكفاءة الاقتصادية لاستخدام العناصر الانتاجية بدالة الناتج الكلي المقدرة،

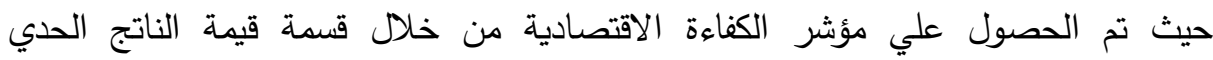
لكل عنصر إنتاجي على سعر وحدة هذا العنصر الإنتاجي(P.M.P)

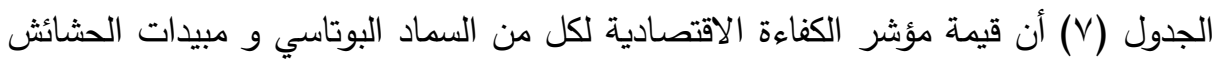
أكبر من الواحد الصحيح مما يثير إلى ارتفاع مستوى الكفاءة الاقتصادية لاستخدام هذهاءه

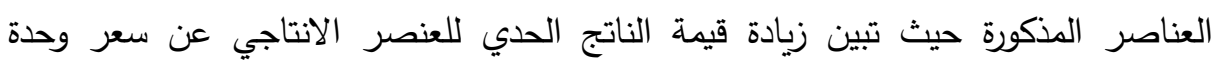

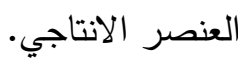

$$
\begin{aligned}
& \text { المجلد الخمسون، العدد الحادي عشر ، الجزء السابع، نوفمبر الr.r } \\
& \text { الترقيم الدولي 0826-1110 1126 } \\
& \text { الترقيم الدولي الموحد الإكتروني 3178-2636 }
\end{aligned}
$$


دالة إنتاج الموالح للفئة الحيازية الثالثة (؟ فدان فأكثر): تم تحديد عناصر الإنتاج ذات التأثير الايجابي المعنوي على إنتاج محصول الموالح في الددى القصير للفئة الحيازية

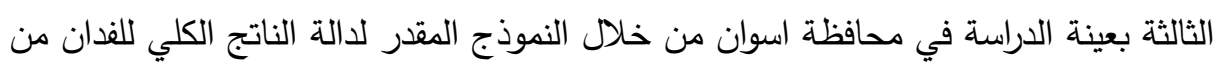

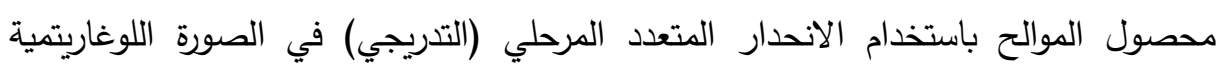

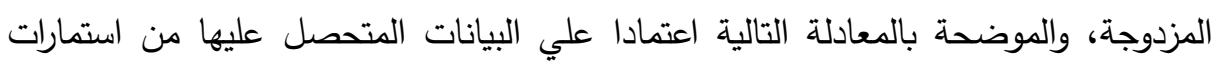

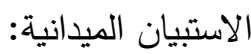

$\operatorname{Ln} \mathrm{Q}=1, \leqslant 0+\cdot, r q r \operatorname{Ln} X 1+\cdot, 1) \leqslant \operatorname{Ln} X 2+\cdot, r q) \operatorname{Ln} X^{\circ}$

$$
\begin{array}{ll}
(r, r r) *(r, r \varepsilon) * & (0, r r)^{* * *} \quad(\varepsilon, 0 \varepsilon) * * \\
\overline{\mathrm{R}}^{2}= & \cdot, r V F=00, r
\end{array}
$$

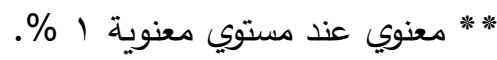

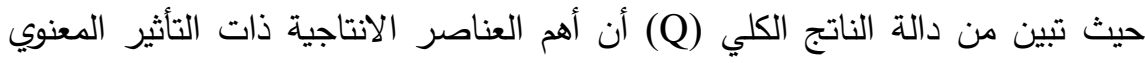

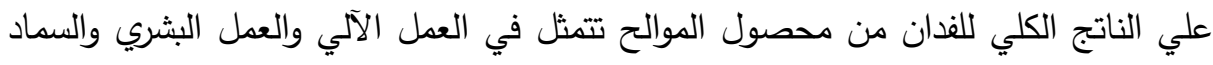

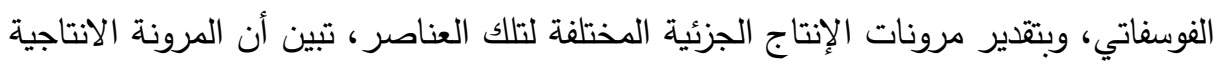

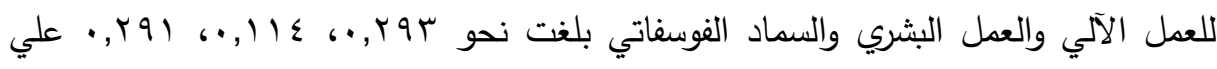

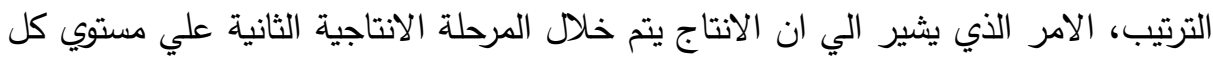

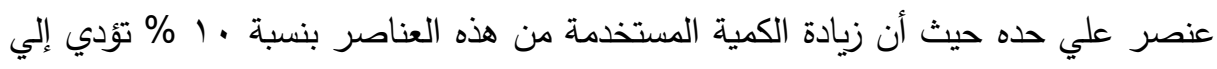

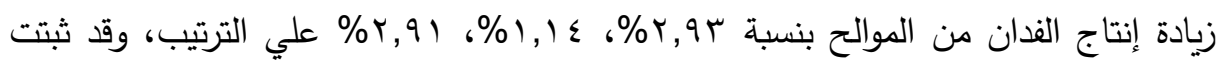

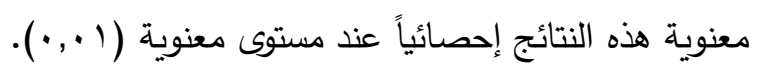

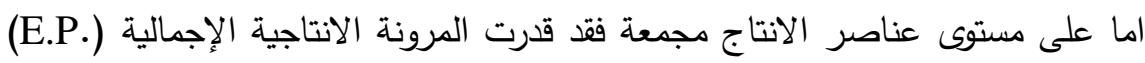

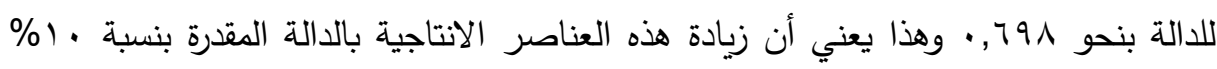

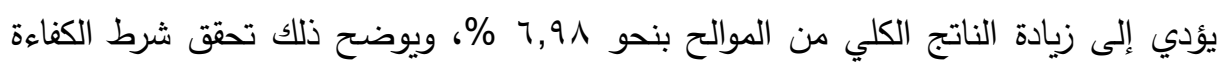

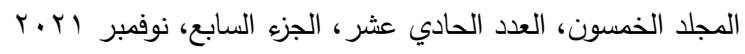

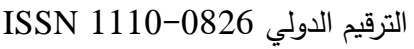

$$
\begin{aligned}
& \text { الترقيم الدولي الموحد الإكتروني 3178-0826-2636 }
\end{aligned}
$$


الاقتصادية على مستوى العناصر الانتاجية وأن الانتاج يتم في المرحلة الثانية للإنتاج

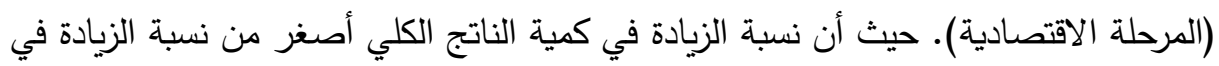

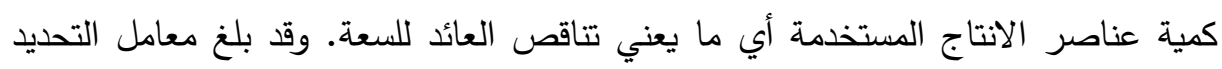
المعدل ( $\left.{ }^{2}\right)$ حوالي VV, . ، مما يثير إلى أن تلك المتغيرات المستقلة المفسرة بالدالة المقدرة

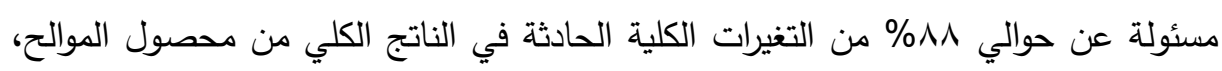
وتثير قيمة (F) إلى المعنوية الإحصائية للدالة المقدرة عند مستوى معنوية (1 ( , •). وتم اشتقاق الناتج الحدي والناتج المتوسط بالنسبة لكل عنصر إنتاجهي إنتاجي في دالة الناتج

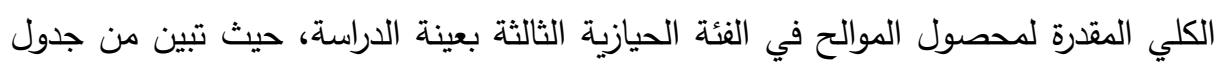

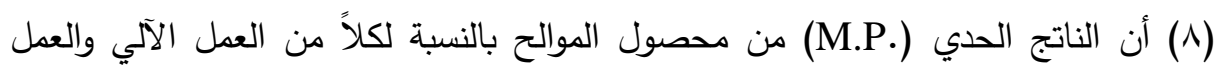

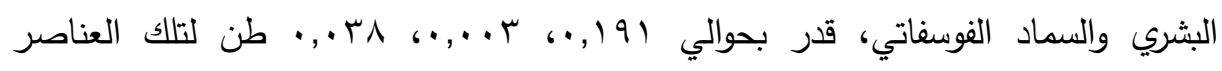
الانتاجية على الترتيب، كما قدرت قيمة الناتج الحدي (V.M.P) لتلك العناصر الانتاجية

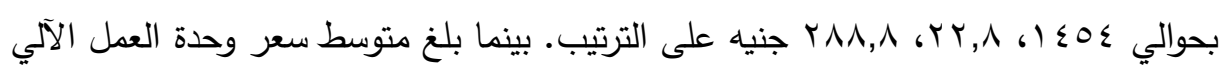

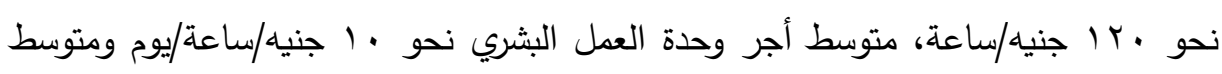

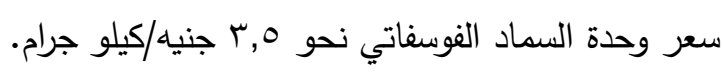

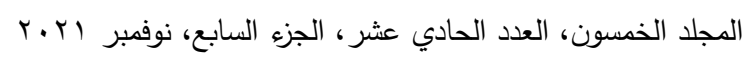

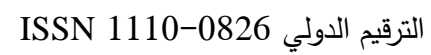

$$
\begin{aligned}
& \text { الترقيم الدولي الموحد الإكتروني 3178-2636 }
\end{aligned}
$$


جدول (^): مؤشرات الكفاءة الاقتصادية لاستخدام عناصر الإنتاج المستخدمة في دالة انتاج الموالح بالفئة الحيازية الثالثة بعينة الدراسة

\begin{tabular}{|c|c|c|c|}
\hline \multicolumn{3}{|c|}{ عناصر الانتاج (المدخلات) في دالة الناتج الكلي } & \multirow{3}{*}{ 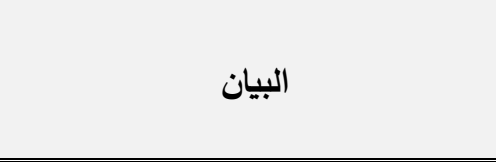 } \\
\hline السماد الفوسفاتي & العمل البشري & العمل الآلي & \\
\hline$X_{5}$ & $\mathbf{X}_{2}$ & $X_{1}$ & \\
\hline TAr & 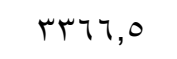 & Ir人 & X \\
\hline \multicolumn{3}{|c|}{9.} & متوسط الناتج الكلي Q' (طن) \\
\hline$\cdot, r 91$ & $\cdot, 11 \varepsilon$ & ש ש & المرونة الانتاجية لعنصر الانتاج (E.X.) \\
\hline \multicolumn{3}{|c|}{$\cdot, 791$} & المرونة الانتاجية الإجمالية (E.P.) \\
\hline 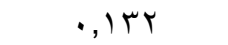 & $\cdot, \cdot Y$ T & . TOY & الناتج المتوسط (A.P.) (طن) \\
\hline$\cdot, \cdot r \mu$ & $\cdot, \ldots r$ & $\cdot, 191$ & الناتج الحدي (M.P.) (طن) \\
\hline$r \wedge \wedge, \wedge$ & $r Y, \Lambda$ & $1 \leqslant 0 \leqslant$ & قيمة الناتج الحدي (V.M.P.) (جنيه) \\
\hline$r, 0$ & 1. & ir. & سعر وحدة عنصر الانتاج (Px) (جنيه) \\
\hline$\wedge r, \varepsilon$ & $r, Y \wedge$ & $1 r, 11$ & الكفاءة الاقتصادية (E.E.) \\
\hline
\end{tabular}

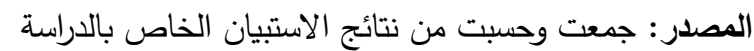

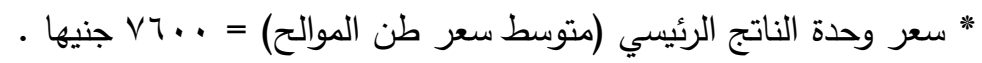

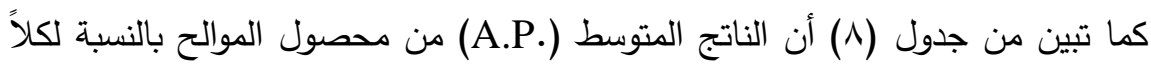

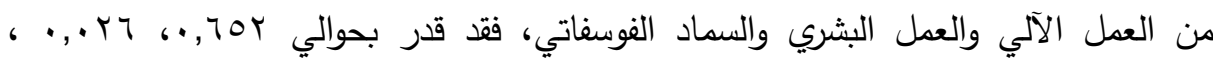
بسا , • طن لتلك العناصر الانتاجية على الترتيب. وتم تقدير الكفاءة الاقتصادية لاستخدام العناصر الانتاجية بدالة الناتج الكلي المقدرة،

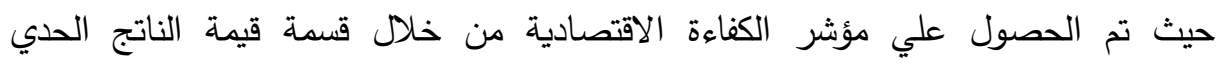
لكل عنصر إنتاجي على سعر وحدة هذا العنصر الإنتاجي (P.M.P)

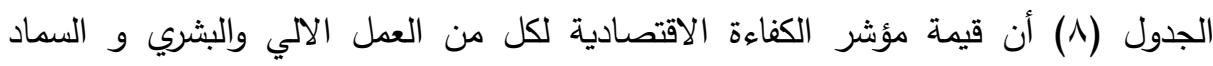

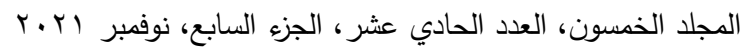

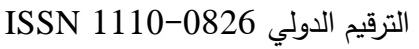

$$
\begin{aligned}
& \text { الترقيم الدولي الموحد الإلكتروني 3178-0826-2636 }
\end{aligned}
$$


الفوسفاتي أكبر من الواحد الصحيح مما يثير إلى ارتفاع مستوى الكفاءة الاقتصادية لاستخدام

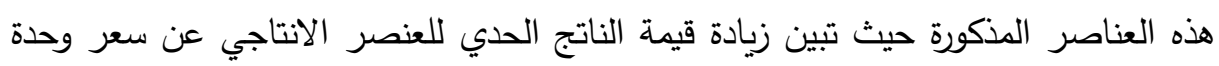

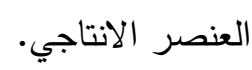

\section{التقدير الإحصائي لاوال تكاليف الموالح بعينة الدراسة:}

دالة تكاليف إنتاج الموالح على مستوى إجمالي العينة (المدى الطويل): بتقدير معالم دالة التكاليف الكلية (T.C) لإتتاج محصول الموالح في المدي الطويل على مستوى إجمالي عينة

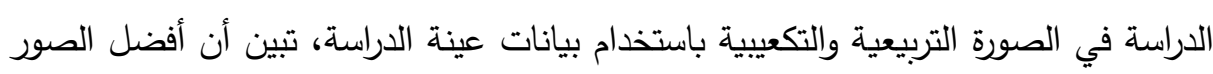

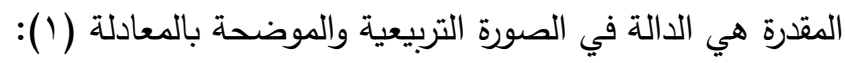
$\mathrm{T} . \mathrm{C}=1797,9 \mathrm{Q}-\mathrm{V}, 1 \leq \mathrm{Q}^{2}+., 1 \mathrm{Q}^{3}$
$(4.2)^{* *}(-\cdot, r r)(r, r)$
$\mathrm{R}^{2}=\cdot, 9$.
$F=1 r \varepsilon, r$

T.C = التكاليف الانتاجية الكلية (جنيه) لإنتاج الموالح على مستوى إجمالي عينة الدراسة.

$$
\begin{aligned}
& \text { = Q الناتج الكلي الفعلي (طن) = Q } \\
& \text { * * معنوي عند مستوي معنوية ا }
\end{aligned}
$$

وتوضح دالة التكاليف الكلية (T.C) لإنتاج محصول الموالح بإجمالي عينة الدراسة، أن

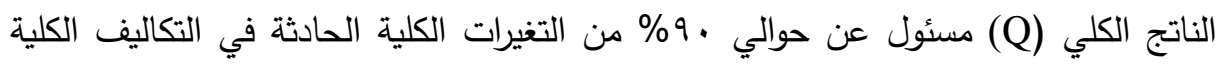
من محصول الموالح

وقدرت دالة التكاليف المتوسطة (A.C) في المدى الطويل من خلال قسمة دالة التكاليف

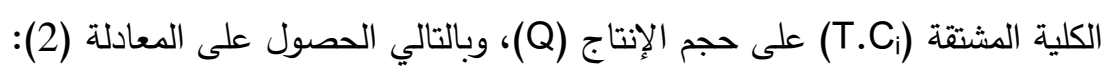

$$
\text { A.C }=1797,9-\vee, 1 \leq Q+\cdot, 1 Q^{2} \leftarrow(Y)
$$

$$
\begin{aligned}
& \text { المجلد الخمسون، العدد الحادي عشر، الجزء السابع، نوفمبر اY.r. }
\end{aligned}
$$

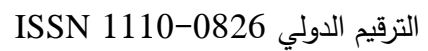

$$
\begin{aligned}
& \text { الترقيم الدولي الموحد الإكتروني 3178-2636 }
\end{aligned}
$$


كما قدرت دالة التكاليف الحدية (M.C) في المدى الطويل من خلال إجراء التفاضل

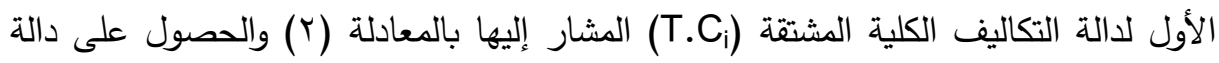
التكاليف الحدية الموضحة بالمعادلة (3):

M.C = 1797, $9-1 \leqslant, r Q+\cdot r Q^{2} \leftarrow(r)$

ويتبين أن حجم الإنتاج الامثل الذي يدني التكاليف لإنتاج الموالح بإجمالي عينة الدراسة

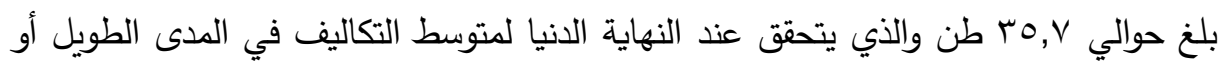
يتحقق عند تساوي التكاليف الحدية (M.C) مع التكاليف المتوسطة (A.C)، وأن حجم الناتج

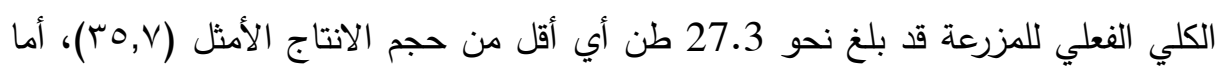

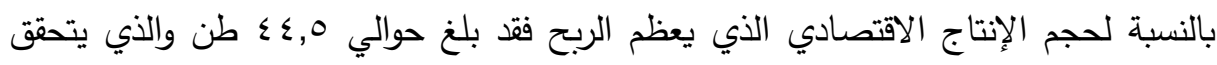

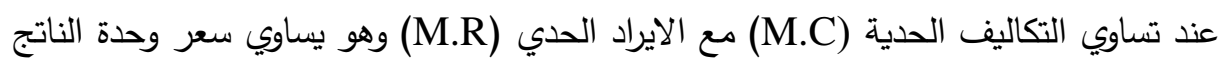

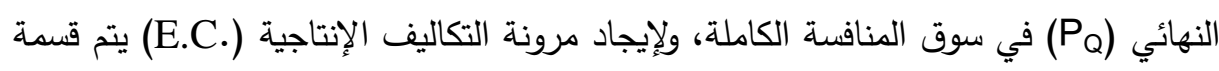
التكاليف الحدية (M.C) على التكاليف المتوسطة (A.C)، حيث بلغت التكاليف الحدية نحو

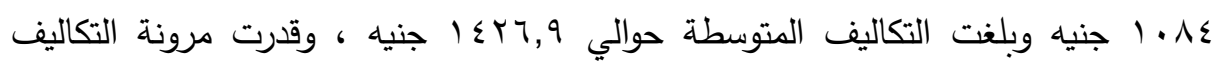

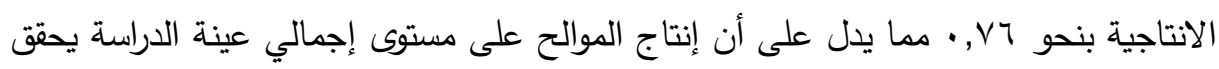
كفاءة اقتصادية نظراً لأن الانتاج يتم في مرحلة تتاقص العائد للسعة، ولا يستطيع المنتج (المزارع) تحقيق وفورات سعة من الانتاج في هذه المرحلة، أي تتاقص العائد للسعة نتيجة لزيادة الانتاج بنسبة أكبر من نسبة الزيادة في التكاليف. دالة تكاليف إنتاج محصول الموالح للفئة الأولي بعينة الدراسة: بتقدير معالم دالة دالة التكاليف الكلية (T.C) لإنتاج محصول الموالح في المدي القصير على مستوى الفئة الحيازية الأولى لئل بمحافظة اسوان في الصورة التربيعية والتكعيبية باستخدام بيانات عينة الدراسة، تبين أن أفضل التصل

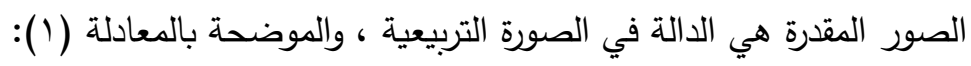

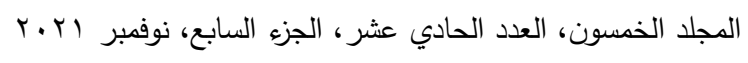

$$
\begin{aligned}
& \text { الترقيم الدولي 0826-0 الترني } \\
& \text { الترقيم الدولي الموحد الإكتروني 3178-2636 }
\end{aligned}
$$




$$
\begin{aligned}
& \text { T.C }=r r \vee \cdot, q+\text { or } \varepsilon, \wedge Q-1 \cdot, \vee Q^{2} \leftarrow(1) \\
& (1, \wedge)(r, 0) *(-r, \varepsilon) * \\
& R^{2}=\cdot, 77 \quad F=11,0
\end{aligned}
$$

$$
\text { حيث: }
$$

T.C التكاليف الانتاجية الكلية (جنيه) لإنتاج الموالح على مستوى الفئة الحيازية الأولى. T.C =Q الناتج الكلي الفعلي (طن).

وتوضح دالة التكاليف الكلية (T.C) لإنتاج محصول الموالح بالفئة الحيازية الأولى، أن

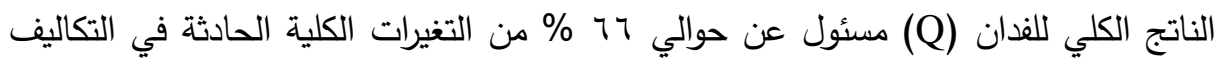
الكلية من محصول الموالح ، كما ثبتت معنوية الدالة ومعلماتها إحصائياً عند مستوى معنوية 1\%، وقدرت دالة التكاليف المتوسطة (A.C) في المدى القصير من خلال قسمة دالة التكاليف الكلية (T.C) على حجم الإنتاج (Q)، وبالتالي الحصول على المعادلة (Y): A.C $=r r V \cdot, q / Q+10 r \varepsilon, \wedge-1 \cdot, V Q \quad \leftarrow(r)$ كما قدرت دالة التكاليف الحدية (M.C) في المدى القصير من خلال إجراء التفاضل الأول لالة التكاليف الكلية (T.C) المشار إليها بالمعادلة (Y) والحصول على الئى دالة التكاليف الحدية الموضحة بالمعادلة (r): M.C $=10 r \leqslant-r_{1}, \varepsilon Q$ $\leftarrow(r)$

ويتبين أن حجم الإنتاج الامثل الذي يدني التكاليف لإنتاج الموالح بالفئة الحيازية الأولى

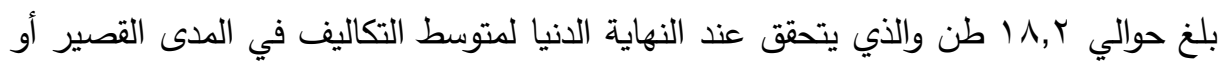
يتحقق عند تساوي التكاليف الحدية (M.C) مع التكاليف المتوسطة (A.C)، وأن حجم الناتج

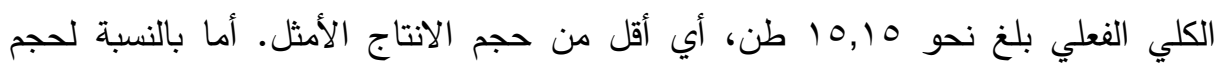

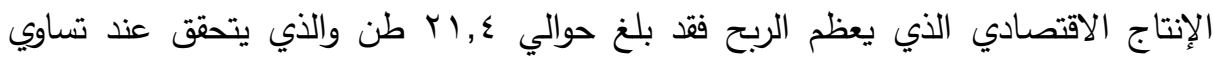

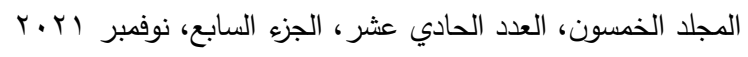

$$
\begin{aligned}
& \text { الترقيم الدولي 0826-08S 1110 } \\
& \text { الترقيم الدولي الموحد الإلكتروني 3178-0826-2636 }
\end{aligned}
$$




\section{مجلة العلوم البيئية \\ كلية الدراسات العليا والبحوث البيئية - جامعة عين شمس \\ ولاء عبد الجواد مصطفى وآخرون}

التكاليف الحدية (M.C) مع الايراد الحدي (M.R) وهو يساوي سعر وحدة الناتج النهائي (PQ) التكاليف الحدية (M.C) على التكاليف المتوسطة (A.C)، حيث بلغت التكاليف الحدية نحو

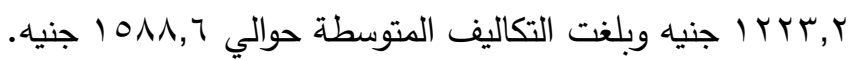

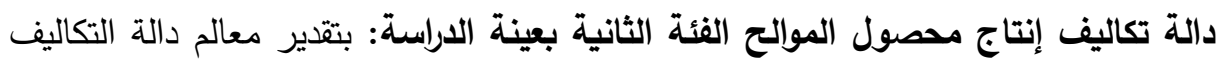
الكلية (T.C) لإنتاج محصول الموالح في المدي القصير على مستوى الفئة الحيازية الثانية بمحافظة اسوان في الصورة التربيعية والتكعيبية باستخدام بيانات عينة الدراسة، تبين أن أفضل

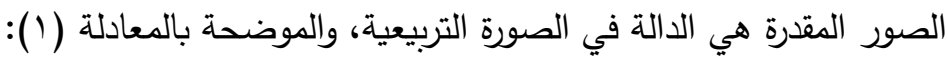
$T . C=\vee\left(\wedge 9,7+r \backslash \wedge \neg, \wedge Q-r r, \cdot r Q^{2} \leftarrow(1)\right.$
(1.1)
$(r .3)^{*}(-1 . \vee)$

$\mathrm{R}^{2}=\cdot, \wedge \wedge$

$$
F=\varepsilon r, 0
$$

T.C = التكاليف الانتاجية الكلية (جنيه) لإنتاج الموالح على مستوى الفئة الحيازية الثانية. =Q الناتج الكلي الفعلي (طن).

وتوضح دالة التكاليف الكلية (T.C) لإنتاج محصول الموالح بالفئة الحيازية الثانية، أن

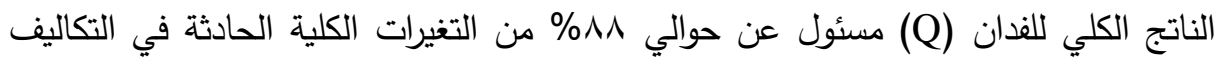

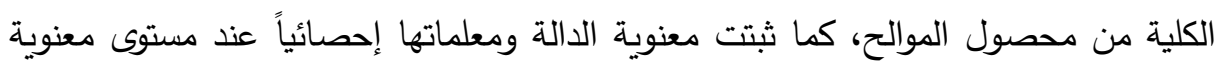
(\%) وقدرت دالة التكاليف المتوسطة (A.C) في المدى القصير من خلال قسمة دالة

التكاليف الكلية (T.C) على حجم الإنتاج (Q)، وبالتالي الحصول على المعادلة (Y): $A . C=V \backslash \wedge 9, \Upsilon / Q+r \mid \wedge T-r r, \cdot r Q \leftarrow(r)$

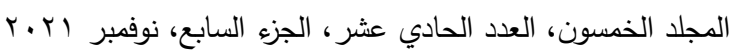

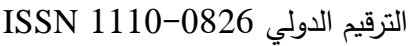

$$
\begin{aligned}
& \text { الترقيم الدولي الموحد الإلكتروني 3178-2636-26 }
\end{aligned}
$$


كما قدرت دالة التكاليف الحدية (M.C) في المدى القصير من خلال إجراء التفاضل الأول لدالة التكاليف الكلية (T.C) بالنسبة لمتغير الانتاج Q المشار إليها بالمعادلة (r) الئل

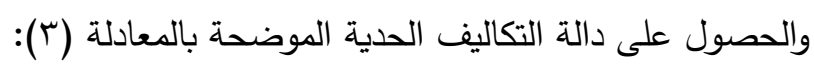

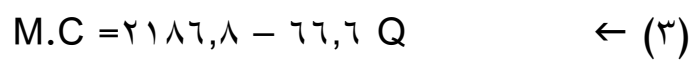
ويتبين أن حجم الإنتاج الامثل الذي يدني التكاليف لإنتاج الموالح بالفئة الحيازية الثانية

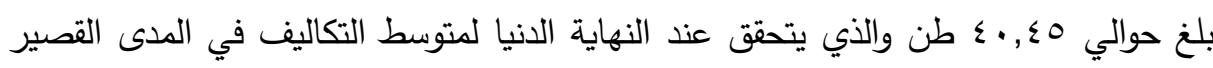

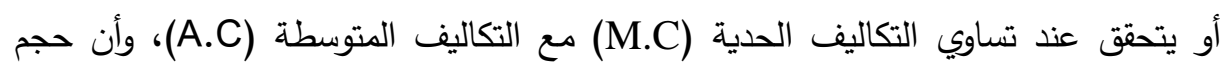

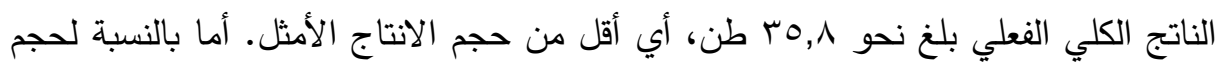

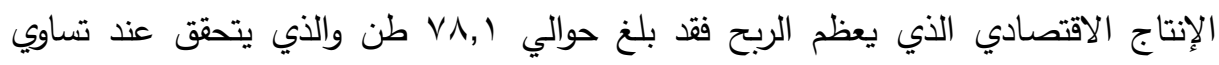
التكاليف الحدية (M.C) مع الايراد الحدي (M.R) وهو يساوي سعر وحدة الناتج النهائي (PQ) التكاليف الحدية (M.C) على التكاليف المتوسطة (A.C)، حيث بلغت التكاليف الحدية نحو مونه

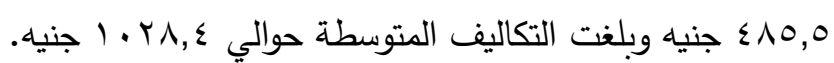
دالة تكاليف إنتاج محصول الموالح بالفئة الثالثة بعينة الدراسة: بتقدير معالم دالم دالة التكاليف الكلية (T.C) لإنتاج محصول الموالح في المدى القصير على مستوى الفئة الحيازية الثالثة

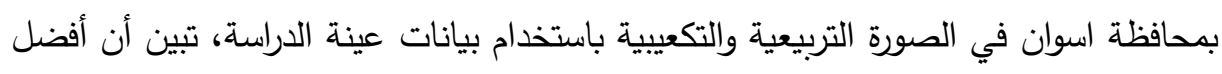

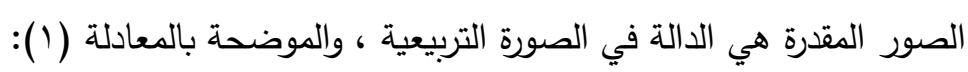

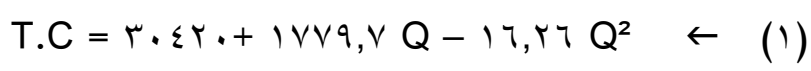

$$
\begin{array}{cc}
(\xi . \Gamma)^{* *}(\xi . \Gamma)^{* *}(-\vee . \Sigma)^{* *} \\
R^{2}=\cdot, \wedge \varepsilon & F=0 \varepsilon, \vee
\end{array}
$$

$$
\begin{aligned}
& \text { المجلد الخمسون، العدد الحادي عشر، الجزء السابع، نوفمبر اY.r. }
\end{aligned}
$$

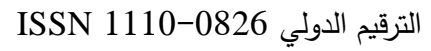

$$
\begin{aligned}
& \text { الترقيم الدولي الموحد الإكتروني 3178-2636 }
\end{aligned}
$$


حيث:

T.C = التكاليف الانتاجية الكلية (جنيه) لإنتاج الموالح على مستوى الفئة الحيازية الثالثة. =Q الناتج الكلي الفعلي (طن).

وتوضح دالة التكاليف الكلية (T.C) لإنتاج محصول الموالح بالفئة الحيازية الثالثة، أن

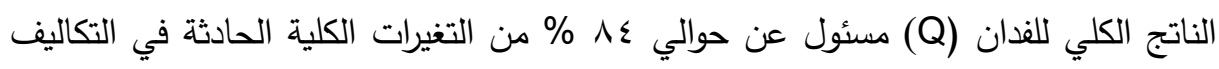

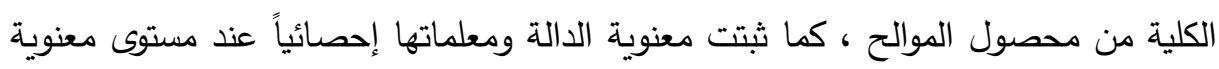
1\%، وقدرت دالة التكاليف المتوسطة (A.C) في المدى القصير من خلال قسمة دالة

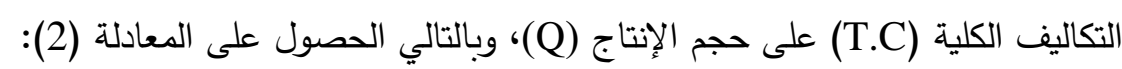
A.C $=r \cdot \varepsilon r \cdot r / Q+1 \vee \vee q, \vee-17, r \uparrow Q \leftarrow(r)$ كما قدرت دالة التكاليف الحدية (M.C) في المدى القصير من خلال إجراء التفاضل الأول لدالة التكاليف الكلية (T.C) المشار إليها بالمعادلة (Y) والحصول على دالة دالة التكاليف الحدية الموضحة بالمعادلة (ץ): $M . C=I \vee \vee q, \vee-r Y$, or $Q$ $\leftarrow(r)$

ويتبين أن حجم الإنتاج الامثل الذي يدني التكاليف لإنتاج الموالح بالفئة الحيازية الثالثة

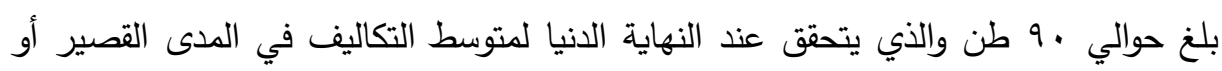
يتحقق عند تساوي التكاليف الحدية (M.C) مع التكاليف المتوسطة (A.C)، وأن حجم الناتج

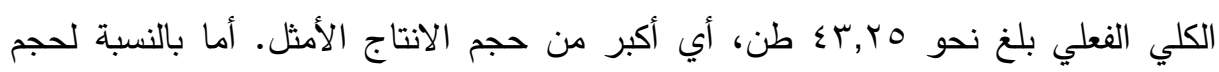

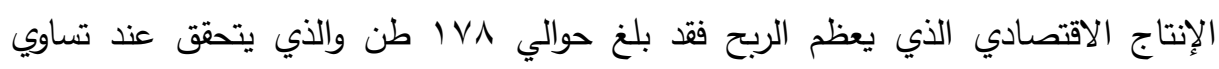
التكاليف الحدية (M.C) مع الايراد الحدي (M.R) وهو يساوي سعر وحدة الناتج النهائي

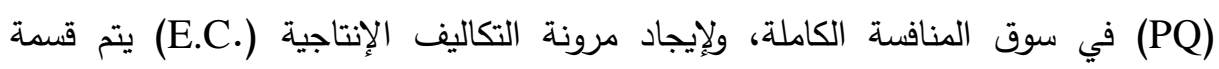
التكاليف الحدية (M.C) على التكاليف المتوسطة (A.C)، حيث بلغت التكاليف الحدية نحو

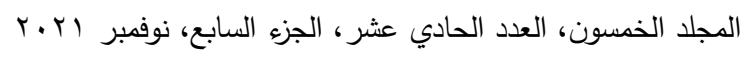

$$
\begin{aligned}
& \text { الترقيم الدولي 0826-0 الترني } \\
& \text { الترقيم الدولي الموحد الإكتروني 3178-2636 }
\end{aligned}
$$


| IIV,1

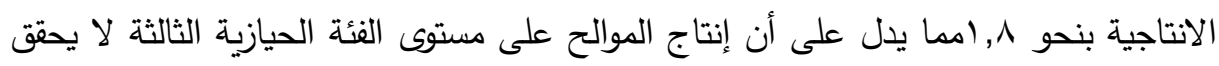

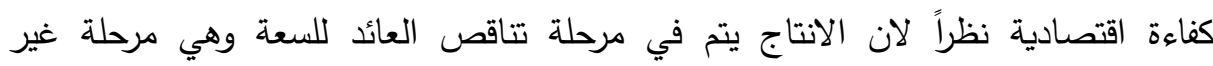

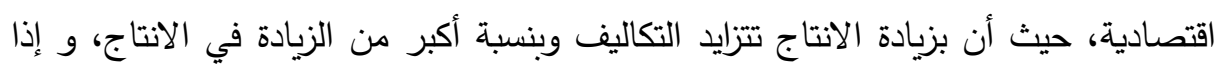

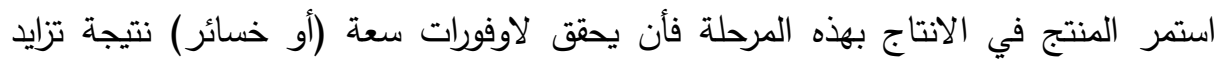

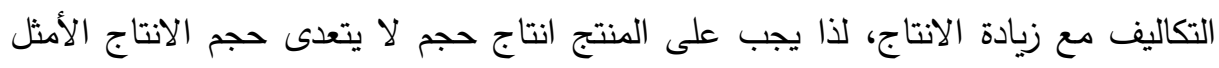
المدني للتكاليف، حتى يتمكن من تحقيق وفورات سعة (أو تزايد العائد للسعة). نتائج استطلاع آراء المبحوثين الخاصة بأهم المشكلات التى تواجه تطبيق واتورات المكافحة الحيوية في عينة الدراسة الميدانية عام 9 أ.ب بمحافظة اسوان.

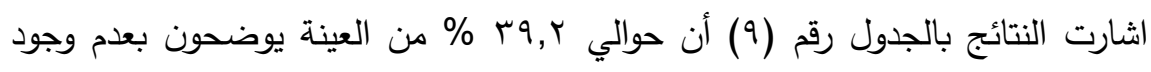

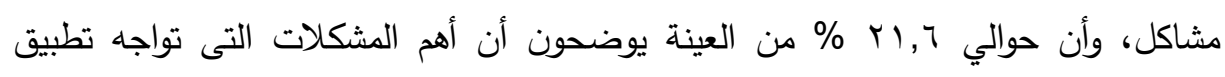
المكافحة الحيوية هي قله خبرة المزارع بطرق الزراعة الحيوية، بينما حوالي ه, ه \% من من العينة يوضحون أن أهم المشكلات التى تواجه تطبيق المكافحة الحيوية هي عدم توافر المعرفة

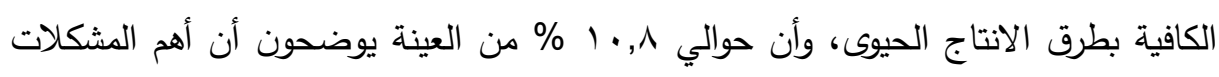

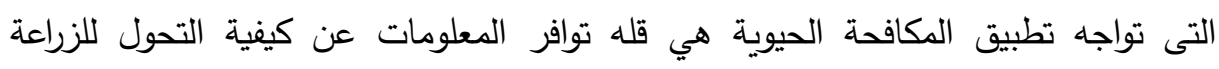
الحيوية، وأن حوالي ^, • ا 1 \% من العينة يوضحون أن أهم المشكلات التى تواجه تطبيق

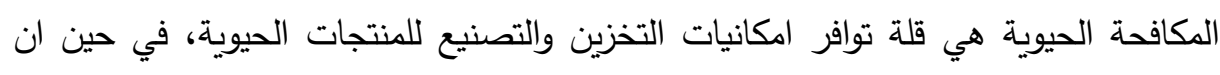
حوالي ^,11 1 من العينة يوضحون أن أهم المشكلات التى تواجه تطبيق الدكافحة الحيوية هي تدريب الكادر الارشادى وذلك من اجمالي عينة الدراسة.

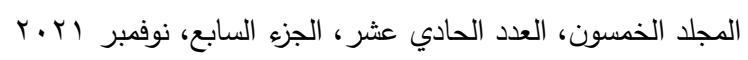

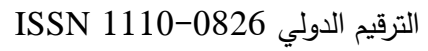

$$
\begin{aligned}
& \text { الترقيم الدولي الموحد الإكتروني 3178-2636 }
\end{aligned}
$$


مجلة العلوم البيئية

كلية الدراسات العليا والبحوث البيئية - جامعة عين شمس لبه

ولاء عبد الجواد مصطفى وآخرون

جدول (9): يوضح أهم المشكلات التي تواجة تطبيق المكافحة الحيوية

\begin{tabular}{|c|c|c|}
\hline$\%$ & 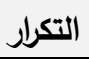 & أهم المثكلات التي تواجة تطبيق المكافحة الحيوية \\
\hline$r q, r$ & $\varepsilon$. & ل الايوجد رد \\
\hline$r 1,7$ & rr & قله خبرة المزارع بطرق الزراعة الحيوية \\
\hline 0,9 & 7 & عدم توافر المعرفة الكافية بطرق الانتاج الحيوى \\
\hline $1 \cdot, \wedge$ & 11 & قله توافر المعلومات عن كيفية التحول للزراعة الحيوية \\
\hline $1 \cdot, \Lambda$ & 11 & قلة توافر امكانيات التخزين والتصنيع للمنتجات الحيوية \\
\hline 11,1 & ir & تدريب الكادر الارشادى \\
\hline $1 \ldots$, & $1 . r$ & الاجمالي \\
\hline
\end{tabular}

المصدر: جمعت وحسبت من استمارة الاستبيان

نتائج استطلاع آراء المبحوثين الخاصة بأهم المقترحات التي يمكن تطبيقها لتقعيل

استخدام المكافحة الحيوية في عينة الدراسة الميدانية عام 9 أب ب بمحافظة اسوان.

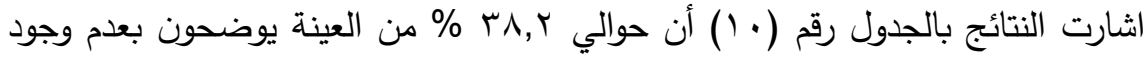

اقتراحات، وأن حوالي ^, • 1 \% من العينة يوضحون أن أهم المقترحات هي الاهتمام بزيادة

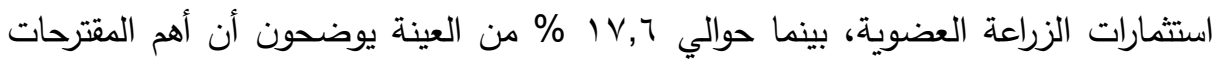

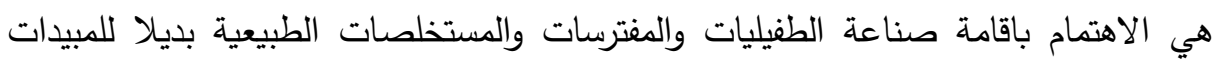

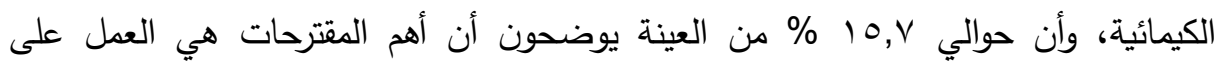

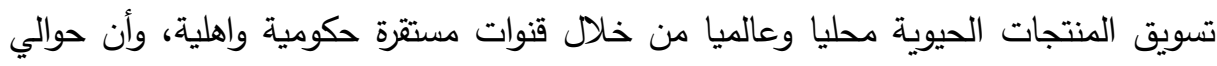

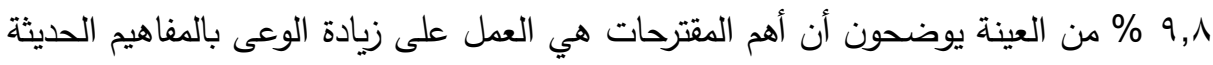

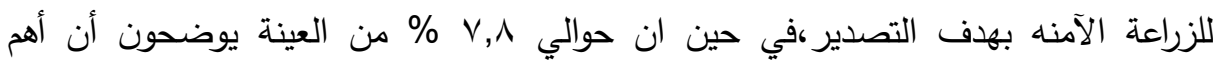

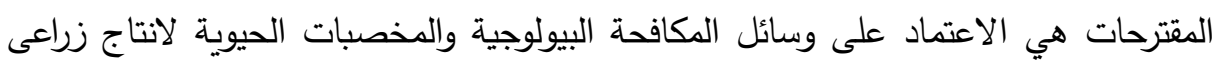
نظيف وآمن على صحة المستهلك وقابل للتصدير وذلك من اجمالي عينة الدراسة.

$$
\text { المجلد الخمسون، العدد الحادي عشر ، الجزء السابع، نوفمبر ابr.r }
$$

$$
\text { الترقيم الدولي 0826-110 110 }
$$

الترقيم الدولي الموحد الإكتروني 3178-2636 
مجلة العلوم البيئية

كلية الدراسات العليا والبحوث البيئية - جامعة عين شمس لائة

ولاء عبد الجواد مصطفى وآخرون

جدول ( • 1): يوضح أهم المقترحات التي يمكن تطبيقها لتفعيل استخدام المكافحة الحيوية

\begin{tabular}{|c|c|c|}
\hline$\%$ & 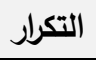 & أهم المقترحات التي يمكن تطبيقها لتفعيل استخدام المكافحة الحيوية \\
\hline rی, & rq & 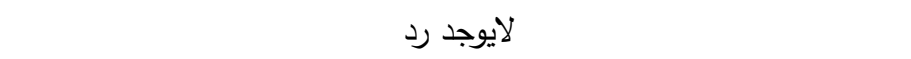 \\
\hline $1 \cdot, 1$ & 11 & الاهتمام بزيادة استثمارات الزراعة العضوية \\
\hline $1 \vee, 7$ & 11 & الاهتمام باقامة صناعة الطفيليات والمفترسات والمستخلصات الطبيعية بديلا \\
\hline $10, \mathrm{~V}$ & 17 & العمل على تسويق المنتجات الحيوية محليا وعالميا \\
\hline $9, \wedge$ & 1. & العمل على زيادة الوعى بالمفاهيم الحديثة للزراعة الآمنه بهدف التصدير \\
\hline$\vee, \wedge$ & $\wedge$ & الاعتماد على وسائل الدكافحة البيولوجية والمخصبات الحيوية \\
\hline $1 \cdots$ & $1 \cdot r$ & 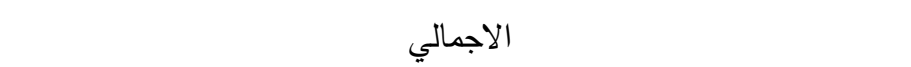 \\
\hline
\end{tabular}

المصدر: جمعت وحسبت من استمارة الاستبيان

التحليل الاحصائي لدراسة أثر المكافحة الحيوية على انتاج الفدان من أهم انواع الموالح بعينة الدراسه:

دراسة العلاقة بين تأثير المكافحة الحيوية وإنتاجية الفدان من البرتقال بالطن بعينه الدراسة: بدراسة العلاقة الانحدارية بين كلاً من المكافحة الحيوية كمتغير مستقل (X) وانتاجية الفدان من البرتقال بالطن كمتغير تابع (Y) بين ان هناك علاقة طردية بين المكافحة الحيوية وانتاجية الفدان للبرتقال بالعينة موضع الدراسة وانه عندما يتم استخدام المكافحة الحيوية يؤدي لئي ذلك الي زيادة انتاجية الفدان من البرتقال بنحو r,r طن للفدان، وبلغ قيمة الارتباط بينهج

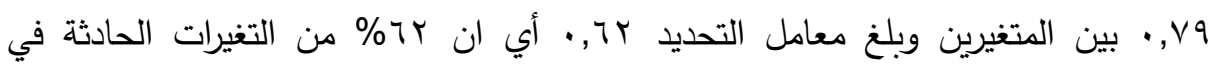

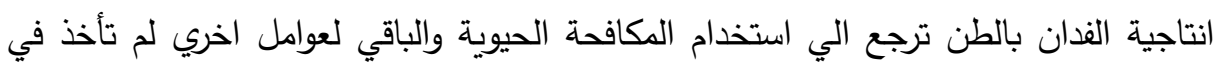

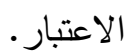

576

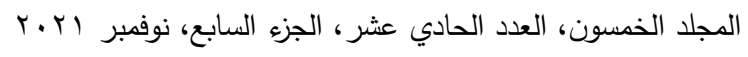

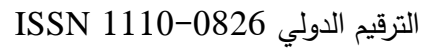

$$
\begin{aligned}
& \text { الترقيم الدولي الموحد الإلكتروني 3178-0826-2636 }
\end{aligned}
$$




$$
\begin{aligned}
& \text { مجلة العلوم البيئية } \\
& \text { كلية الدراسات العليا والبحوث البيئية - جامعة عين شس البية } \\
& \text { ولاء عبد الجواد مصطفى وآخرون }
\end{aligned}
$$

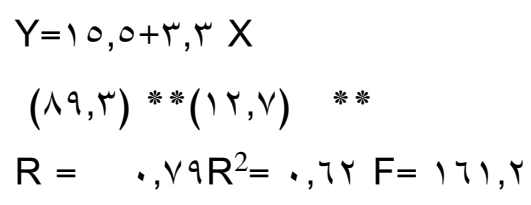

$$
\begin{aligned}
& \text { حيث: } \\
& \text { Y : انتاجية الفدان من البرتقال بعينة الدراسة. } \\
& \text { X } \\
& \text { القيمة الموجودة بين الأقواس تشير إلى قيمة (T) المحسوبة } \\
& \text { (R) معامل التحديد، (R) معامل الارتباط. } \\
& \text { (F) معنوية النموذج ككل. (F) } \\
& \text { المصدر : استمارة الاستبيان }
\end{aligned}
$$

دراسة العلاقة بين تأثير المكافحة الحيوية وانتاجية الفذان من الليمون بالطن بعينه الاراسة: بدراسة العلاقة الانحدارية بين كلاً من المكافحة الحيوية كمتغير مستقل (X) وانتاجية الفدان من الليمون بالطن كمتغير تابع(Y) بين ان هناك علاقة طردية بين المكافحة الحيوية وانتاجية

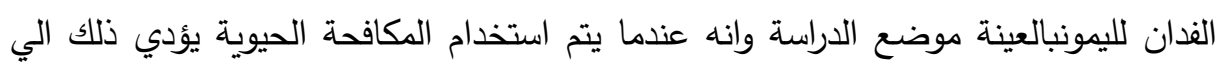

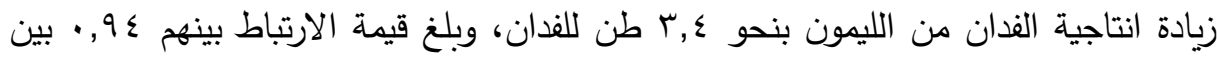

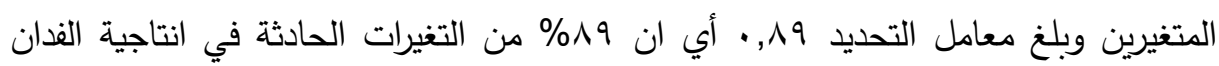
بالطن ترجع الي استخدام المكافحة الحيوية والباقي لعوامل اخري لم تأخذ في الاعتبار . $Y=r \cdot, \tau+r, \varepsilon X$

$$
\begin{aligned}
& (r \circ \neg, \varepsilon) * *(r \wedge, q) \\
& R=\quad \cdot, 9 \leqslant R^{2}=\cdot, \wedge q F=\wedge \mu \circ, 1
\end{aligned}
$$

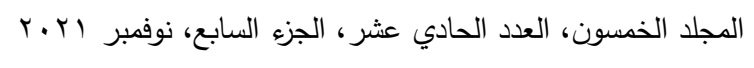

$$
\begin{aligned}
& \text { الترقيم الدولي 0826-0 1110 } \\
& \text { الترقيم الدولي الموحد الإكتروني 3178-2636 }
\end{aligned}
$$


Y : انتاجية الفدان من الليمون بعينة الدراسة.

X

القيمة الموجودة بين الأقواس تثير إلى قيمة ( T ) المحسوبة (R2) معامل التحديد (R) معامل الارتباط.

(F)

المصدر : استمارة الاستبيان

دراسة العلاقة بين تأثير المكافحة الحيوية وإنتاجية الفدان من الجريب فروت بالطن بعينه

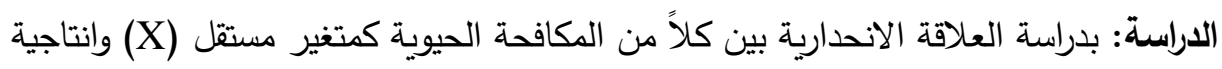
الفدان من الجريب فروت بالطن كمتغير تابع (Y) بين ان هنالك علاقة طردية بين المكافحة الحيوية وانتاجية الفذان من الجريب فروت موضع الدراسة وانه عندما يتم استخدام المكافحة

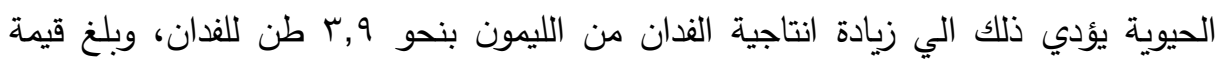

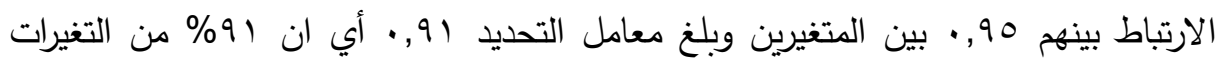

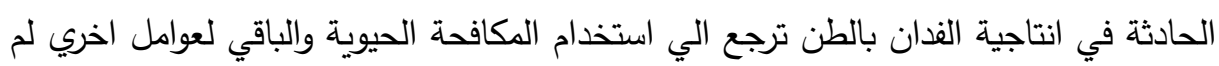

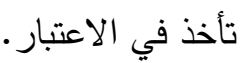

$Y=r \cdot, \varepsilon+r, q X$

$(r \leq V, r) * *(r), V)$

$\left.\mathrm{R}=\quad \cdot, 90 \mathrm{R}^{2}=\cdot, 9\right) \mathrm{F}=1 \ldots \varepsilon, r$

انتاجية الفدان من الجريب فروت بعينة الدراسة.

X

578

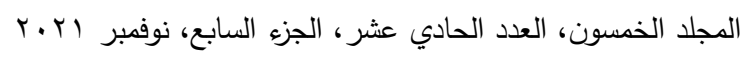

$$
\begin{aligned}
& \text { الترقيم الدولي 0826-0 التئي } \\
& \text { الترقيم الدولي الموحد الإكتروني 3178-2636 }
\end{aligned}
$$


القيمة الموجودة بين الأقواس تثير إلى قيمة ( T) المحسوبة

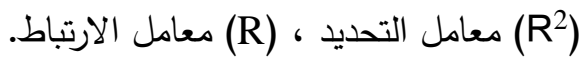

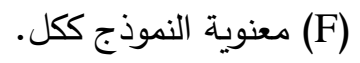
المصدر : استمارة الاستبيان

\section{اللموصياهيت}

زيادة كميات السماد البوتاسي والمبيدات الخاصة بمقاومة الآفات والحشائش بالحد الذي يسمح بمعظمة الانتاج في الفئة الثانية.

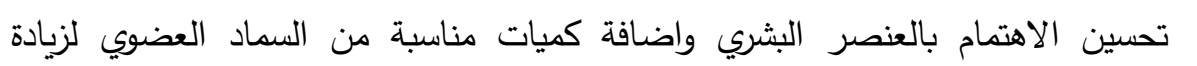
الانتاج ومستوي الكفاءة الاقتصادية للموالح في المزارع الاقل من ه هـئ فدان.

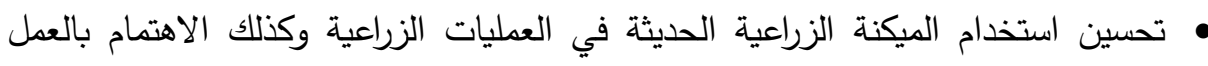
البشري واضافات الكميات المناسبة بين السماد الفوسفاتي وذلك لتحقيق افضل انتاج

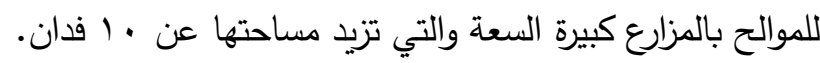

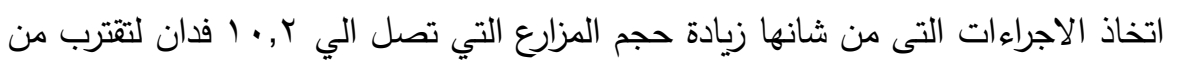
الحجم الامثل والذي تم اشتقاقة من دوال تكاليف في المدى الطويل. تخصيص مناطق معنية لزراعة الموالح للتغلب على مشاكل التصدير بدلا من الاعتماد على تصدير الفائض. • العمل على التوسع فى فتح أسواق جديدة للتصدير للتغلب على ارتفاع التكاليف التى تواجه

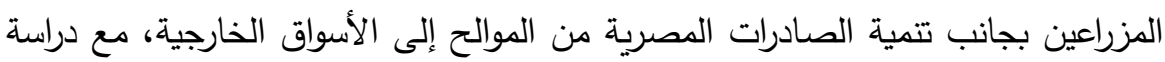
احتياجات الأسواق من الموالح وخاصة الأسواق الأوروبية وتحديد التوقيت للطلب عليها.

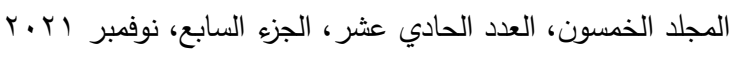

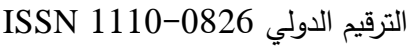

$$
\begin{aligned}
& \text { الترقيم الدولي الموحد الإلكتروني 3178-2636-2682 }
\end{aligned}
$$




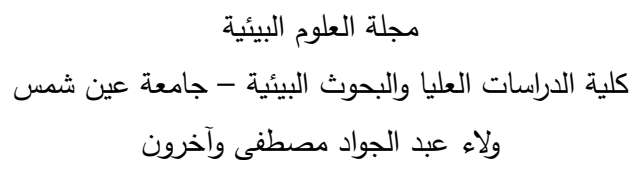

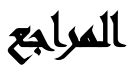

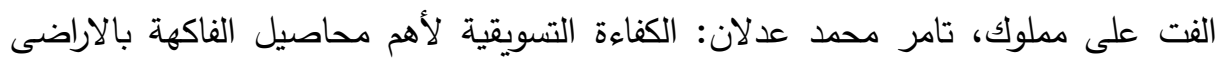

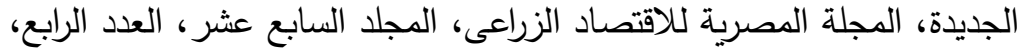

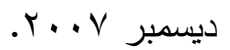

طه عبد الله نصر (r/911): الفواكة المستديمة الخضرة والمتساقطة الاوراق، كلية الزراعة،

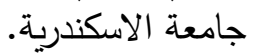

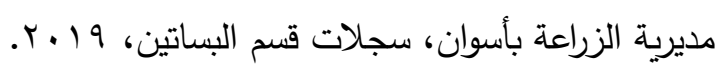

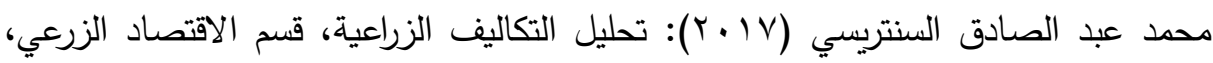
كلية الزراعة، جامعة عين شمس.

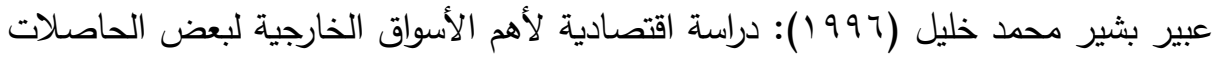

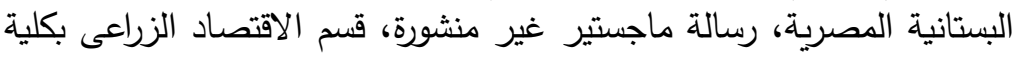

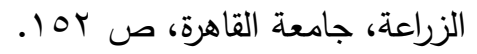

وزارة الزراعة واستصلاح الاراضي، قطاع الثئون الاقتصادية، نشرة المساحة المحصولية،

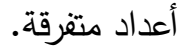

أحمد أحمد جويلي (9VI ( )): مبادىء التسويق الزراعي ، دار الهنا للطباعة، الطبعة الأولى.

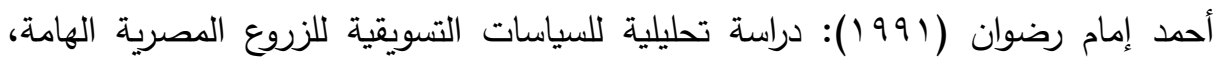

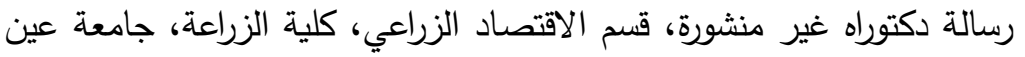

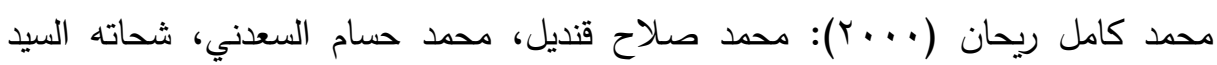

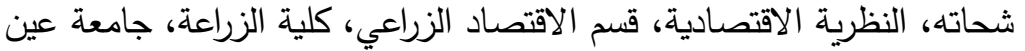

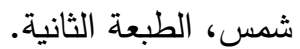

580

$$
\begin{aligned}
& \text { المجلد الخمسون، العدد الحادي عشر ، الجزء السابع، نوفمبر اYr.r } \\
& \text { الترقيم الدولي 0826-08S 1110 تصني } \\
& \text { الترقيم الدولي الموحد الإكتروني 3178-2636 }
\end{aligned}
$$




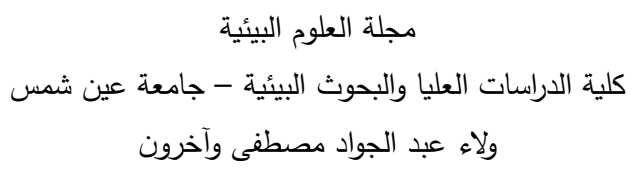

\title{
AN ECONOMIC AND ENVIRONMENTAL STUDY FOR CITRUS PRODUCTION IN ASWAN GOVERNORATE
}

\author{
Walaa A. Moustafa ${ }^{(1)}$; Siham A. Hashem ${ }^{(2)}$ \\ and Ayman M. Ibrahim ${ }^{(1)}$
}

1) Plant Protection Research Institute, Agriculture Research Center 2)Department of Environmental Agricultural Science, Faculty of Graduate Studies and Environmental Research, Ain Shams University

\begin{abstract}
This study aims to determine production costs functions which reflect the relationship between total costs and actual production, from which it is possible to derive the most important economic indicators that reflect the extent to which agricultural production units achieve economic efficiency in their use of productive resources participating in the production process, as well as the extent to which these are achieved. Units of profit maximization of the agricultural product. The production functions were estimated in the total category, and the marginal product and the average product were derived for each production element in the estimated total product function of the citrus crop for the total sample of the study. It was estimated at about 0.011, $0.124,0.037$ tons for those production elements, respectively, and the Value of the marginal Product (VMP) for those production elements was estimated at about $82.5,930,277.8$ pounds, respectively, while the average wage of the human labor unit was about 10 pounds / hour / day The average price of an organic fertilizer unit is about 75 pounds $/ \mathrm{m} 3$, and the average price of a phosphate fertilizer unit is 3.5 pounds $/ \mathrm{kg}$.

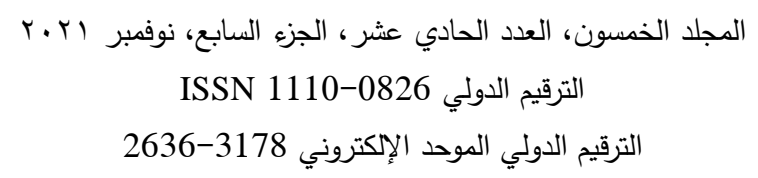




$$
\begin{aligned}
& \text { مجلة العلوم البيئية } \\
& \text { كلية الدراسات العليا والبحوث البيئية - جامعة عين شمس لإسل } \\
& \text { ولاء عبد الجواد مصطفى وآخرون }
\end{aligned}
$$

It was also found that the Average Yield (A.Y.) of the citrus crop in relation to both human labor, organic fertilizer and nitrogen fertilizer was estimated at about $0.023,0.33,0.126$ tons for those production elements, respectively.

Key words: cost functions, production functions, economic efficiency, and optimum volume of production.

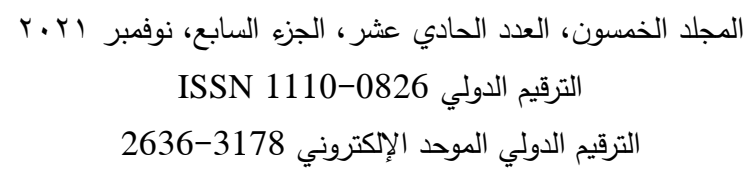

